\title{
Novel Mesoporous Silica Materials with Hierarchically Ordered Nanochannel: Synthesis with the Assistance of Straight-Chain Alkanes and Application
}

\author{
Haidong Zhang ${ }^{1}$ and Xiaohong $\mathrm{Li}^{2}$ \\ ${ }^{1}$ Engineering Research Centre for Wasted Oil Recovery Technology of Ministry of Education, Key Laboratory of Catalysis Science and \\ Technology of Chongqing Education Commission, Chongqing Technology and Business University, Chongqing 400067, China \\ ${ }^{2}$ Shanghai Key Lab of Green Chemistry and Chemical Processes, School of Chemistry and Molecular Engineering, \\ East China Normal University, Shanghai 200062, China
}

Correspondence should be addressed to Haidong Zhang; haidongzhang@ctbu.edu.cn and Xiaohong Li; xhli@chem.ecnu.edu.cn

Received 2 October 2015; Accepted 22 December 2015

Academic Editor: Khaldoun Bachari

Copyright (C) 2016 H. Zhang and X. Li. This is an open access article distributed under the Creative Commons Attribution License, which permits unrestricted use, distribution, and reproduction in any medium, provided the original work is properly cited.

The straight-chain alkane-assisted synthesis of hierarchical mesoporous silica materials (MSM) results in variable mesostructures and morphologies due to remarkably different self-assembly routes of template agent from those without the assistance of straightchain alkanes. The textural properties, particularly pore size, channel structure, morphology, and hierarchical structure of those MSM make them demonstrate peculiar effects in the immobilization of homogeneous catalysts.

Dedicated to Professor Yi-Meng Wang

\section{Introduction}

In the past two decades, ordered MSM have received much attention due to their tunable mesostructure, systematically tailored pore architecture, and their applications in adsorption, separation, catalysis, drug delivery, photonic, and nanosized semiconductors [1-8]. The preparation of MSM is based on the use of structure-directing agents, which are normally organic molecules or supramolecules of surfactants and polymers, for example, $\mathrm{EO}_{20} \mathrm{PO}_{70} \mathrm{EO}_{20}$ (Pluronic P123) for SBA15 type MSM $[9,10]$, Pluronic F127 for SBA-16 type MSM [11], cetyltrimethylammonium bromide $\left(\mathrm{C}_{16} \mathrm{H}_{33} \mathrm{~N}\left(\mathrm{CH}_{3}\right)_{3}\right.$ $\mathrm{Br}, \mathrm{CTAB})$ for MCM-41 [3-5, 12] and MCM-48 [13, 14] types MSM, and biodegradable polyethylene oxide (PEO) surfactants for MSU-X type MSM [15-18]. Besides these supramolecules and polymers, some other materials like resin [19] and DNA [20] can also be used to prepare MSM. Particularly, the SBA-15 type MSM have attracted extraordinarily high attention because of their large pore size ranging from 4.6 to $30 \mathrm{~nm}$, uniform ordered mesoporous channels, high specific surface area, connectivity of the mesoporous channels, and higher hydrothermal stability than some other MSM $[1,9,10$, 21, 22].

In the preparation of MSM, the methods to tune the porosity, pore morphology, size distribution, and the hierarchical morphology of these materials are of particular interests. According to current knowledge, cooperative assembly between template molecules and silica precursors is generally involved to form mesostructured organic/inorganic composites during the preparation of MSM. The mesostructure can be maintained after removal of template. In other words, the formation of the ordered mesopores, specific morphology, and textural characteristics of final products is decided by the nanostructure of the self-assembled hybrid micelles of organic template molecules and inorganic framework species. The factors including hydrolysis and condensation of silicate 


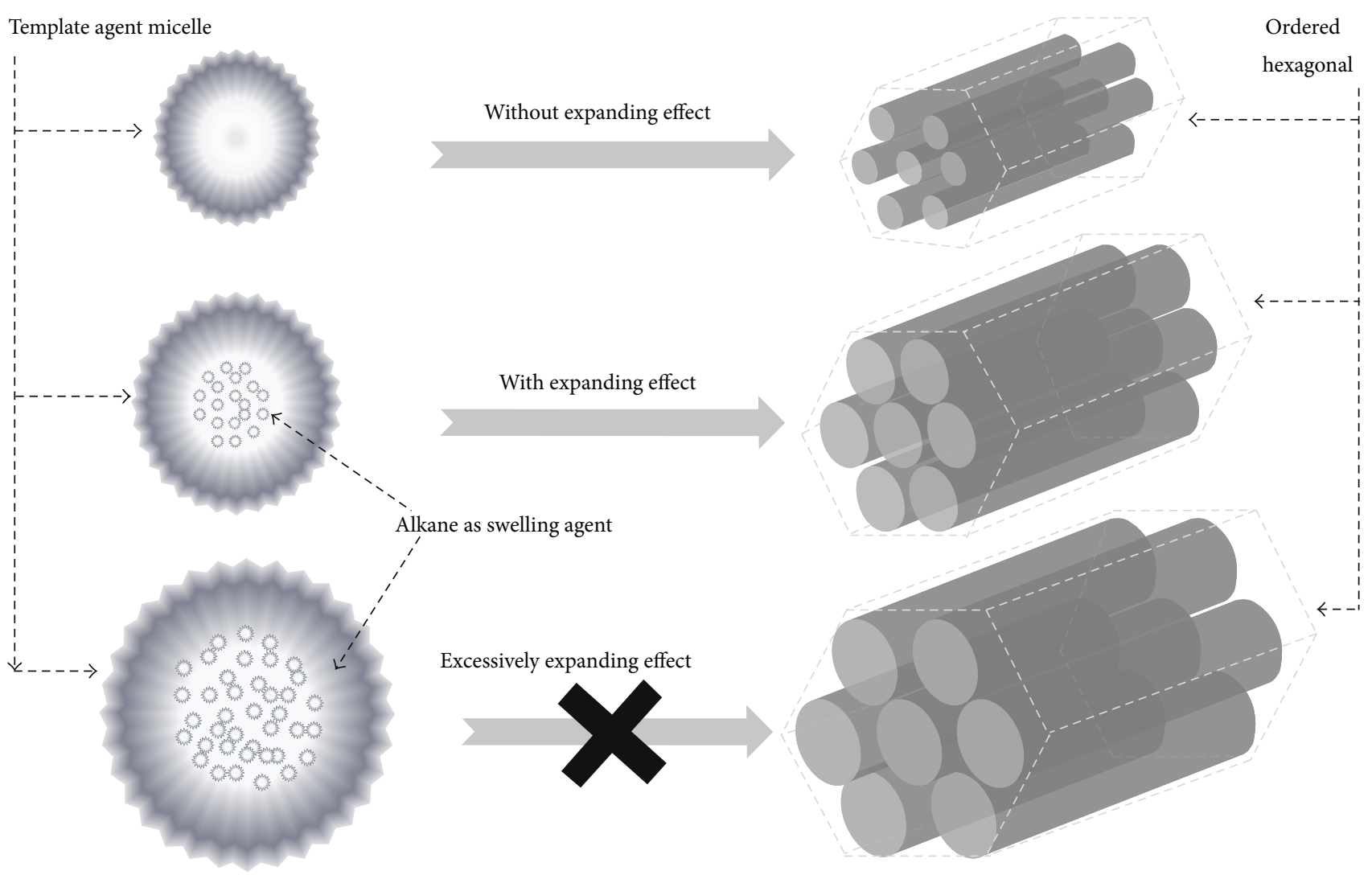

FIGURE 1: Tuning the pore size of ordered MSM with alkanes as swelling agents.

species, the shape of micelles, inorganic salts, organic swelling agents, cosolvents, and cosurfactants are found to affect the morphology of final products [21, 23-27].

One important finding in this field is that the addition of some pore expanders, for example, alkanes and aromatics, into the synthetic mixtures can greatly change the mesostructure and specific morphology of final products [28]. These pore expanders, for example, 1,3,5-trimethylbenzene (TMB) $[9,10,29-32]$, ethylbenzene [33], decane [31, 34-36], hexane [37-39], heptane [30, 37], nonane [37], 1,3,5-triisopropylbenzene (TIPB)/cyclohexane [40-42], octane [43], and N,Ndimethylhexadecylamine [44], act as swelling agents and lead to enlarged micelle size of templates and subsequently enlarged pore size as illustrated in Figure 1. In novel gemini surfactant system, decane was also employed to tune the pore size and mesostructure of MSM [45]. However, the pore expanding agents typically result in a decrease in mesostructure ordering and even a dramatic change in the type of mesostructure (e.g., from hexagonally ordered SBA15 to mesocellular foam) while they readily increase the pore size and volume of micelle-templated materials [28]. In some cases, those swelling agents can remarkably change the particle morphology of obtained ordered MSM. While those micelle expanders, which show the excessively strong and thus poorly controlled swelling behavior, were used, it is hardly to simply enlarge the pore size without any changes in morphology, ordering, and type of mesostructure.
In this minireview paper, we focus on the effect of the addition of straight-chain alkanes in the syntheses processes of ordered MSM on their textural characteristics and specific morphology. The applications of these mesoporous silica materials prepared with the assistance of straight-chain alkanes in the fields such as catalysis, separation, and drug delivery are also presented.

\section{Straight-Chain Alkane-Assisted Synthesis of Mesoporous Silica}

\subsection{Synthesis without Phase Separation}

2.1.1. Pore Expanding Effect of Alkanes. The employment of various organic molecules as swelling agents to expand the pore size of mesoporous silica materials has a history almost as long as that of MSM themselves [3, 46]. In most cases, TMB was used as a competent swelling agent for the pore expansion of two major families of MSM, MCM-41 [3, 46] and SBA-15 $[9,10]$, due to the hydrophobic interactions of its aromatic structure with template molecules. With the assistance of inorganic salt, TMB and P123 could be employed to synthesize highly ordered face-centered cubic (fcc) LPFDU-12 MSM with large pores (up to $27 \mathrm{~nm}$ ) and unit cells (up to $44 \mathrm{~nm}$ ) at low temperatures [47].

Ulagappan and Rao used straight-chain alkanes $\left(\mathrm{C}_{n} \mathrm{H}_{2 n+2}\right.$, $n=5$ to 20) as swelling agents in the pore expansion of 

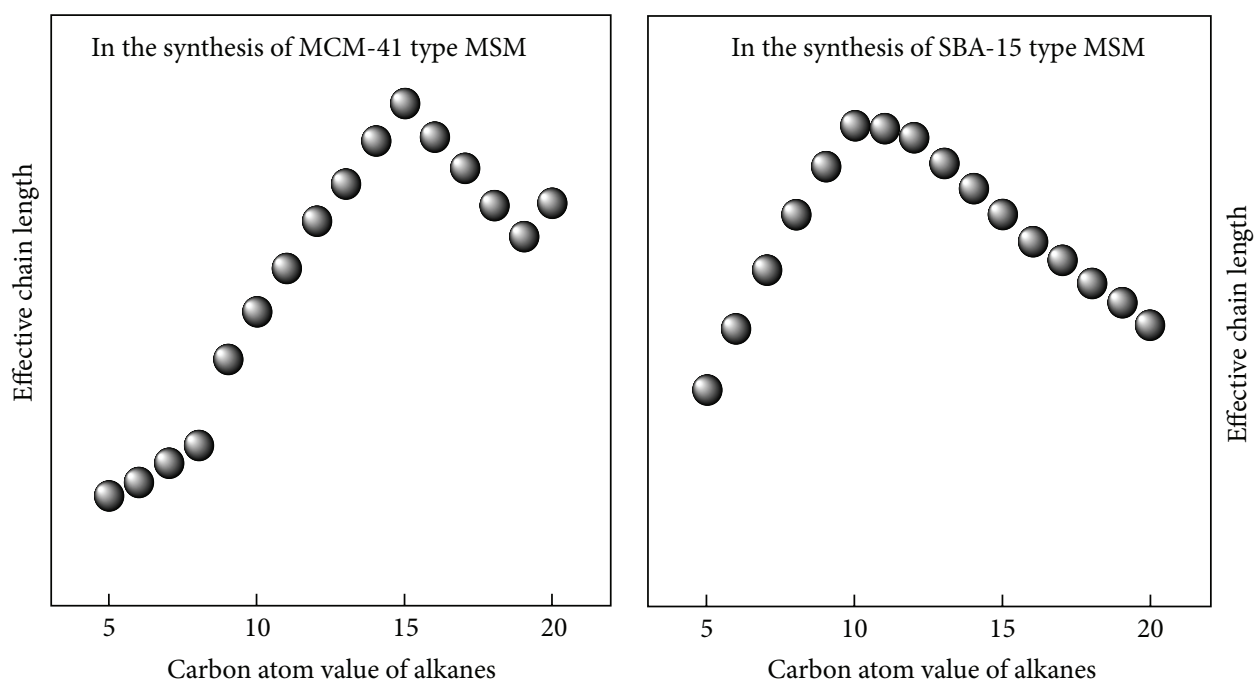

Figure 2: Effective chain length of $n$-alkanes as swelling agent $[34,37,43,48,50,51,55,56]$.

the MSM templated by CTAB [48]. They found that the alkanes with $n=9$ to 15 showed best behavior towards the pore expansion in mesoporous silicas, where the increase in $\mathrm{d}_{100}$ is close to the theoretic chain length of those alkanes. They suggested that a core of alkanes with $n=9$ to 15 is surrounded by a layer of surfactant CTAB, with a one-to-one alignment of the alkane chain and the surfactant tail. In case of the alkanes with $n=5$ to 8 , small increases in the $d_{100}$ value were observed, compared to the entire chain length of the alkanes. Differently, the alkanes with $n=5$ to 8 may be dispersed between the tails of the surfactant molecules, and thus the entire chain length of the alkanes is not involved in enlarging the size of the surfactant micelles. Higher alkanes with $n>15$ also cannot result in significant pore expansion, suggesting that these chains may not be rigid enough and thus contribute less to pore expanding than those with $n$ from 9 to 15 . Conversely, in the synthesis of SBA-15 type MSM, a decrease in the alkane chain length from 12 to 6 carbon atoms led to a unit-cell size enlargement from 13 to $16 \sim 17 \mathrm{~nm}$ and pore diameter increasing from 12 to $16 \mathrm{~nm}[37,51]$. This is consistent with the findings of Nagarajan; that is, the uptake of liner alkanes by micelles of Pluronic copolymers was rather small and it increases as alkanes chain length decreases [54].

Jana et al. investigated the pore expanding effect of some linear alkanes including octane, nonane, decane, tridecane, hexadecane, and eicosane in the synthesis of SBA-15 type materials [50]. They used a triblock copolymer [poly(ethylene glycol $)_{20}$-poly(propylene glycol) ${ }_{70}$-poly(ethylene glycol $)_{20}$ ] (Dai-ichi Kogyo Seiyaku, Japan) as the substitute for P123. Being different to some other studies $[9,10]$, they did not add the triblock copolymer into $\mathrm{HCl}$ solution but into deionized water to form a template- $\mathrm{H}_{2} \mathrm{O}$ solution, followed by the addition of TEOS and $\mathrm{HCl}$, step by step. They found that the use of octane and nonane could only lead to the formation of disordered MCF but the use of decane, tridecane, hexadecane, and eicosane could result in ordered hexagonal mesostructure of SBA-15 type MSM. The pore size of obtained
MSM is increased to $22.7 \mathrm{~nm}$ in the presence of octane $\left(\mathrm{C}_{8} \mathrm{H}_{18}\right)$, whereas it is increased to $8.4,8.5,8.8,10.1$, and $14.0 \mathrm{~nm}$ in the presence of hexadecane $\left(\mathrm{C}_{16} \mathrm{H}_{34}\right)$, tridecane $\left(\mathrm{C}_{13} \mathrm{H}_{28}\right)$, eicosane $\left(\mathrm{C}_{20} \mathrm{H}_{42}\right)$, decane $\left(\mathrm{C}_{10} \mathrm{H}_{22}\right)$, and nonane $\left(\mathrm{C}_{9} \mathrm{H}_{20}\right)$, respectively. This generally reflects that longer chain length of alkane leads to smaller pore diameter of resultant SBA-15 materials, but such trend is not linear and the reason for this gradual decrease had not been discussed. Actually, their finding is materially consistent with that discovered by Ulagappan and Rao [48] in the synthesis of MCM-41 type MSM and that discovered by Sun et al. [37] and Zhang et al. [51] in the synthesis of SBA-15 type MSM.

These findings suggest that the effective chain length of $n$-alkane should be considered while employed as swelling agent in the synthesis of MSM (see Figure 2) [34, 37, 43, 48, $50,51,55,56]$. In the synthesis of SBA-15 type mesoporous silicas with P123 as template agent, the effective chain length almost increases linearly with increasing $n$ value and thus the corresponding expanding effect also increases linearly for those $n$-alkanes $\left(\mathrm{C}_{n} \mathrm{H}_{2 n+2}\right)$ with $n=5$ to 9 . The effective chain length of the $n$-alkanes with $n=10$ to 15 does not increase but decrease with $n$ value and longer alkane leads to smaller pore diameter. In the synthesis of MCM-41 type MSM using $\mathrm{CTAB}$ as template, the effective chain length increases linearly with $n$ value for those $n$-alkanes $\left(\mathrm{C}_{n} \mathrm{H}_{2 n+2}\right)$ with $n=9$ to 15 and $\mathrm{C} 15 \mathrm{H} 32$ shows the highest effective chain length. In the synthesis of Ti-HMS molecular sieve with $n$-hexane and $n$-octane as pore expanders [57], it was also found that the pore diameter of Ti-HMS increased with the increase in the dosage of alkanes and the number of carbon atoms in alkane molecules.

2.1.2. Effect of Alkanes on Morphology. The alkanes used as swelling agent in the synthesis of MSM can lead to not only the expanded pore diameter but also the lowering of the degree of structural ordering and further change of the structure type [28]. In the studies of Ulagappan and Rao on 


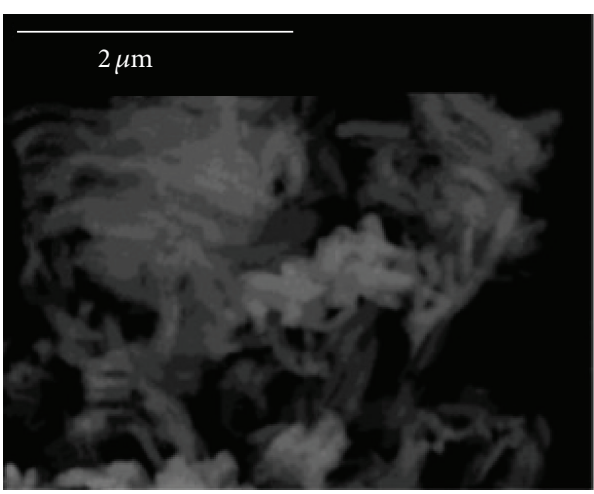

(a)

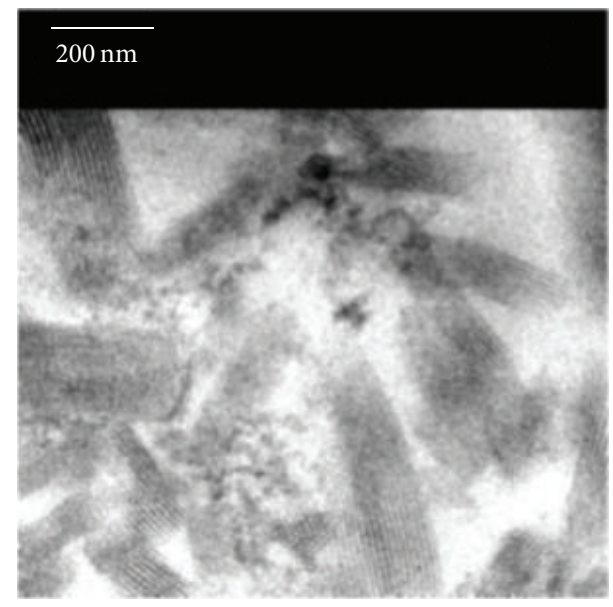

(c)

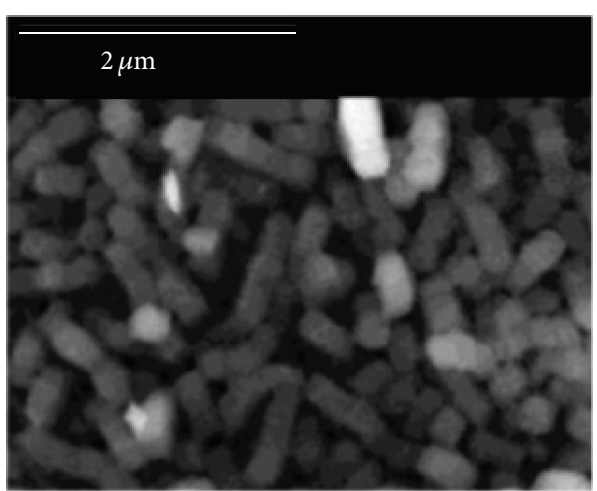

(b)

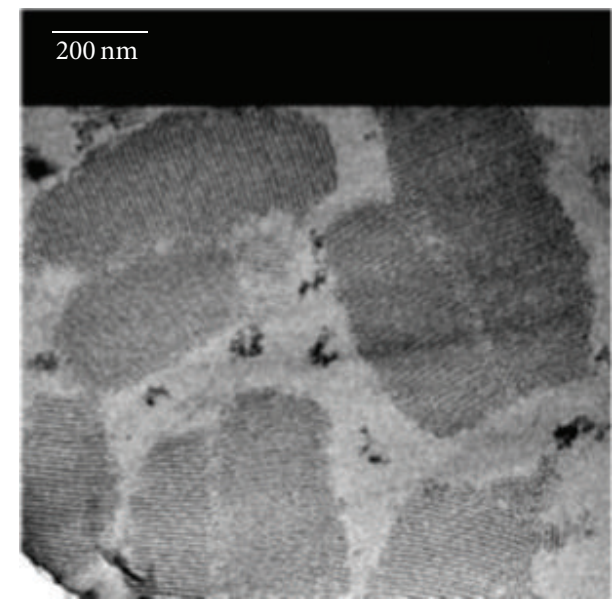

(d)

FIGURE 3: SEM images (a-b) and TEM images (c-d) of mesoporous silica SBA-15 synthesized at different weight ratios of decane to P123 in the presence of $\mathrm{NH}_{4} \mathrm{~F}$ : (a) and (c) $0.4: 1$; (b) and (d) $5.8: 1$. Reprinted with permission from [34]. Copyright (2004) American Chemical Society.

the effect of different $n$-alkanes on the synthesis of MCM41 type MSM, the disordering or variability of mesostructure was observed with the addition of $n$-alkanes [48]. Jana et al. also found that the use of decane, tridecane, hexadecane, and eicosane could result in ordered hexagonal mesostructure of SBA-15 type MSM but the use of octane and nonane could not [50].

Zhang et al. reported for the first time the use of $n$ decane as the swelling agent in the preparation of a novel type of mesoporous SBA-15 material with unconventional short channels running along the short axis of particles [34]. They used large amount of $n$-decane (with a typical weight ratio of decane to P123 at $5.8: 1$ ) as cosolvent to synthesize unusual SBA-15 material with cuboid-like morphology and large pore size. The average pore size of this SBA-15 material is around $12.1 \mathrm{~nm}$, which is remarkably larger than that of classic SBA-15 materials, due to the foreseeable expanding effect of $n$-decane $[9,10]$. More interestingly, the channel length of this SBA-15 material is decided by the size of these cubo-like particles, which are about $500 \mathrm{~nm}$ long and $200 \mathrm{~nm}$ wide (see Figure 3 ). The ratio of $n$-decane to P123 was suggested to be the key point that affects the mesostructure of final products. Low ratio of decane to P123 at $0.4: 1$ showed unapparent effect on the morphology of the obtained SBA-15 material, which is fiber-like and similar to the classic SBA-15 materials. While the decane/P123 ratio increases to $5.8: 1$, the change of morphology from fiber-like to cubo-like takes place. Further increase of decane/P123 ration to $7.6: 1$ leads to no further expanding of pore size and its effect on morphology and mesostructure of nanochannels was not mentioned.

$\mathrm{TMB} / \mathrm{P} 123$ weight ratio should be kept less than $0.3: 1$ to obtain hexagonally ordered SBA-15 materials while TMB is used as a swelling agent [29]. The TMB/P123 weight ratio higher than $0.3: 1$ will lead to disordered mesocellular foam (MCF). Although Zhang et al. mentioned that the amount of $n$-decane used in their preparation was probably enough to form microemulsion, no phase transition was observed when their synthesis process was carried out in a homogeneous mixture of $\mathrm{P} 123-\mathrm{H}_{2} \mathrm{O}$-decane. They suggested a side-on mechanism (see Figure 4) of condensation between short silicate-doped micelles, similar to the mechanism suggested by Ulagappan and Rao [48]. In such condensation mechanism, $n$-decane in the micelles of P123 acts as swelling agent and then expands the pore diameter. However, the driving force to speciate formation of such novel cubo-like morphology was still indistinct. 

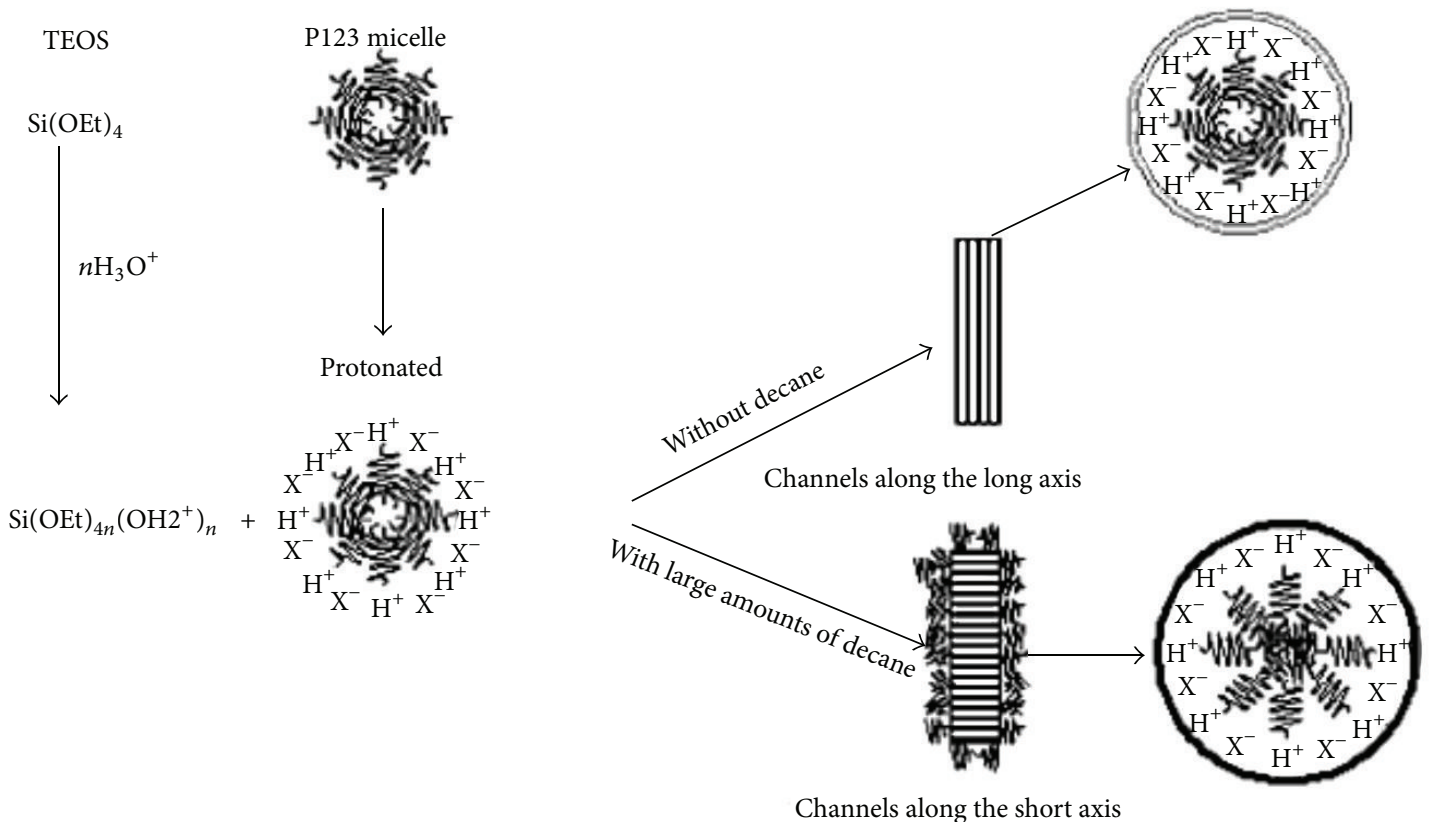

Mr Molecule of surfactant
Mr Molecule of decane

FIGURE 4: Schematic representation of the bifunctional roles of large amounts of decane. Reprinted with permission from [34]. Copyright (2004) American Chemical Society.

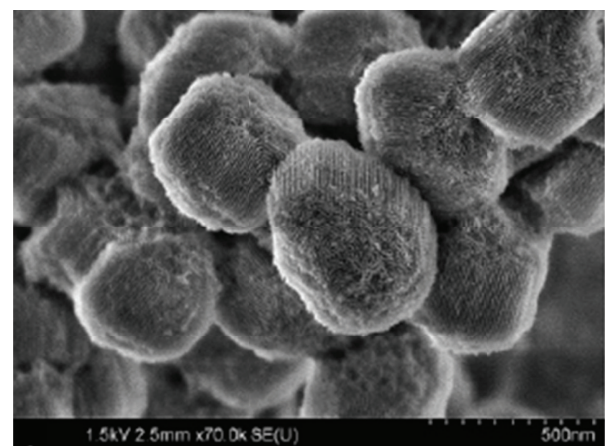

FIGURE 5: HRSEM image of the SBA-15 mesoporous silica resulting from the use of decane. Reprinted with permission from [51]. Copyright (2006) American Chemical Society.

Actually, the TEM image of this SBA-15 with short channels looks more like the cross section [51] of a platelet-like $[58,59]$ or a short rod-like [60] SBA-15 materials, as short nanochannels (100-300 nm long) could run parallel to the thickness of the nanostructured hexagonal platelet-like or rod-like particles. The high-resolution TEM (HRTEM) image of such SBA-15 sample prepared with a decane/P123 ratio at $5.8: 1$ intensifies such hypothesis [34]. The further studies on the effect of $n$-decane indicated that such abovementioned short channel SBA-15 silica might also be a tower/platelet-like SBA-15 silica (see Figure 5) [51]. Additionally, the repetition of

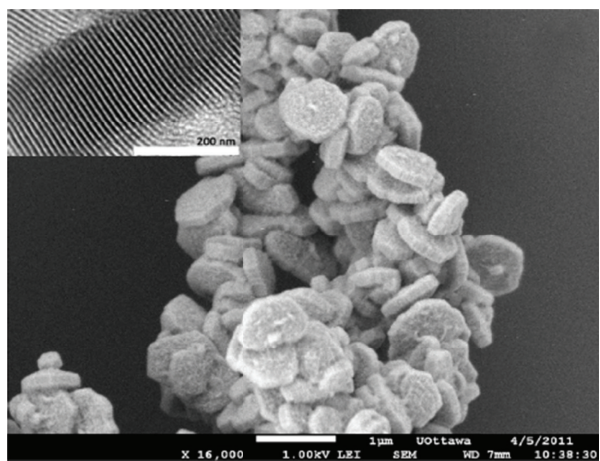

FIGURE 6: SEM image of the platelet-like SBA-15 mesoporous silica resulting from the use of decane. Reprinted with permission from [61]. Copyright (2011) American Chemical Society.

the same synthetic process by other researchers indicated that this synthetic system leads to platelet-like SBA-15 type silica (see Figure 6) [61].

Low decane/P123 ratio can also distinctly affect the morphology and ordering of resultant product, reflecting the perturbation effect of $n$-decane on the self-assembly of P123 micelles [34]. Although the pore size related to decane/P123 ratio at $0.4: 1$ was not provided, the obtained fiber-like SBA-15 materials was remarkably shorter and thinner than classic SBA-15 materials. This is agreed with the findings of Ulagappan and Rao [48]. 
Secondly, the addition of $\mathrm{NH}_{4} \mathrm{~F}$ was considered as a crucial factor for the formation of highly ordered hexagonal mesoporous structure, while only disordered MSM can be obtained without the addition of $\mathrm{NH}_{4} \mathrm{~F}$ [34]. $\mathrm{F}^{-}$, as a mineralizing agent, is commonly used in the synthesis of zeolite and some mesoporous materials. Fluoride not only accelerates hydrolysis and polymerization of silica species, but also increases the solubility of certain tri- and tetravalent elements through complexation, allowing well mineralization as well as substantial ordering and significant improvement in mesostructure and macromorphology in aqueous acid media.

Sun et al. [37, 43, 56] and Zhang et al. [51] systematically studied the effect of the addition of some different straight-chain alkanes $\left(n-\mathrm{C}_{n} \mathrm{H}_{2 n+2}\right)$ on the mesostructure and morphology control of MSM, with carbon number $n=5$ (pentane), 6 (hexane), 7 (heptane), 8 (octane), 9 (nonane), 10 (decane), 11 (undecane), and 12 (dodecane). Two major modifications to the syntheses were made $[37,43,51,56]$, comparing with the abovementioned synthesis of SBA-15 type mesoporous silica with the assistance of decane [34]. The first one is the way to add alkanes into reaction mixture. In the report [34], decane was firstly added into a clear solution of $\mathrm{P} 123-\mathrm{HCl}-\mathrm{H}_{2} \mathrm{O}$, followed by the addition of $\mathrm{NH}_{4} \mathrm{~F}$ and tetramethoxyorthosilane (TMOS) in sequence. In their follow-up studies, hexane $[37,51,55]$, heptane $[37,55,56]$, octane $[51,55,56]$, nonane $[37,51,55,56]$, decane $[51,55,56]$, undecane [55], and dodecane $[51,55,56]$, alkanes, and TEOS were premixed and then added into the clear solution of P123 in $\mathrm{HCl}$. The second modification was the concentration of $\mathrm{HCl}$ solution used in the synthesis, which was increased from $1.07 \mathrm{M}$ [34] to $1.20-1.30 \mathrm{M}[37,43,51,56]$. Noticeably, the molar ratios of template to alkanes in the studies of Sun et al. [37, 43, 56], Sun et al. [56], and Ulagappan and Rao [48] were distinctly different. Ulagappan and Rao kept the molar ratio of template to alkane at $1: 1$ since this ratio was optimal for obtaining the maximum possible pore size with a given alkane just as in the case of TMB [46]. Sun et al. [37, 55, 56] and Zhang et al. [51] took the molar ratio of template to alkane ranging from $134: 1$ to $755: 1$. These synthesis processes were all based on the cooperation of straight-chain alkanes and micelles of P123 in homogeneous phase. It was strange that the formation of any microemulsion/emulsion had not been observed during these synthesis processes $[34,37,43,51,56]$, because the formation of $\mathrm{O} / \mathrm{W}$ microemulsion/emulsion is reasonable or even inevitable with such high molar ratio of surfactant to alkane [62-66].

Because of the two major modifications mentioned above, no such novel short channels as those parallel channels running along the short axis [34] can be observed in the synthesis processes assisted by the straight-chain alkanes with relatively short chain length [37]. Hexane $\left(\mathrm{C}_{6} \mathrm{H}_{14}\right)$, heptane $\left(\mathrm{C}_{7} \mathrm{H}_{14}\right)$, and nonane $\left(\mathrm{C}_{9} \mathrm{H}_{20}\right)$ were used as swelling agents in the synthesis of highly ordered SBA-15 materials with the help of $\mathrm{NH}_{4} \mathrm{~F}$ and exhibited an increasing ability to expand the pore size of SBA-15 silica with a decrease in chain length of these three alkanes [37]. The largest pore size $(15.7 \mathrm{~nm})$ of SBA-15 silica was achieved with the addition of hexane, which has the shortest chain length among these three alkanes.
The specific area of the obtained SBA-15 silica is inversely proportional to pore size. Shorter chain length of alkane results in lower specific area and larger pore size. Notably, the effect of hexane, heptane, and nonane on the pore size of SBA-15 type mesoporous silica is opposed to that found in the synthesis of MCM-41 type mesoporous silica with CTAB [48].

In addition, the initial reaction temperature of hydrolysis was found to be a key point to form hexagonally ordered mesostructure. For each alkane among hexane, heptane, and nonane, a critical temperature was found to lead to the phase transition from hexagonally ordered mesostructure to disordered MCF type mesostructure [37]. Such critical temperature was found to be $17^{\circ} \mathrm{C}, 22^{\circ} \mathrm{C}$, and $27^{\circ} \mathrm{C}$ for hexane, heptane, and nonane, respectively. The initial reaction temperature of hydrolysis must be lower than these critical ones to form highly hexagonally ordered mesostructure. Similar request of low reaction temperature was also found in the synthesis of SBA-15 type mesoporous silica with 1,3,5-triisopropylbenzene (TIPB) as a micelle expander [58]. Cao and Kruk used $n$ hexane as swelling agent and low temperature $\left(15^{\circ} \mathrm{C}\right)$ of initial synthesis condition, similar to that of Sun et al. [37], to obtain highly ordered SBA-15 silica materials with pore diameters ranging from 12 to $18 \mathrm{~nm}$ [67]. Sun et al. studied the effect of chain length of straight-chain alkanes $(n=6-12)$ on the pore enlargement [55]. With or without alkane addition, the phase of surfactant micelle evolutes in a way of amorphous $\rightarrow$ hexaganol $\rightarrow$ vesicle-like/hexaganol $\rightarrow$ vesiclelike $\rightarrow$ vesicle-like/foam-like $\rightarrow$ foam-like with increasing temperature of initial synthesis. The phase-transformation temperature is linearly proportional to carbon number, where the optimized temperature of initial synthesis for achieving highly hexagonally ordered mesostructure increases with chain length of alkanes. Notably, the presence of vesiclelike mesostructure indicates the formation of $n$-alkane-P123$\mathrm{H}_{3} \mathrm{O}^{+}$microemulsion system in this study.

Different mesostructure of MSM can be varied by careful control over the phase behavior of water-alkane-surfactant synthetic mixture. The effect of alkane/surfactant ratio and TEOS/P123 ratio on the phase evolution in water-alkanesurfactant mixture was synergistically studied by Sun et al. [56] and Zhang et al. [51]. With the decane/P123 molar ratio increasing from $134: 1$ to $755: 1$, the obtained SBA-15 materials evolute from chain-like arrays of independent particles to loosely stacked independent particles and finally to a laminalike aggregate of independent particles. All these independent particles of SBA-15 materials are highly ordered with a $2 \mathrm{D}$ hexagonal symmetry (p6 mm) and exhibit the morphology similar to that of tower-like SBA-15 [49]. The proposed formation route [51] of these SBA-15 materials is a reprint of the one proposed for the formation of tower-like SBA-15 materials [49].

The effect of different TEOS/P123 molar ratio with a fixed decane/P123 molar ratio at 235 was also investigated [51]. With increasing TEOS/P123 molar ratio from 48 to 110, the obtained SBA-15 materials show 2D hexagonal symmetry (p6 mm) but the morphology varies from fiber-like bundle (TEOS/P123 = 48:1) to loosely stacked independent particles $($ TEOS $/ \mathrm{P} 123=60: 1)$, platelet-like particles $(\mathrm{TEOS} / \mathrm{P} 123=$ $77: 1$ ), and free-standing films (TEOS/P123 = $110: 1$ ). Notably, 
while TEOS/P123 molar ratio reaches $110: 1$, the yield of such free-standing films was around 50\%, and some aggregated irregular particles were also observed besides these independent films. Similarly, a decrease in the ordering of MSM can also occur while the alkane/P123 molar ratio reaches a high value [68]. In the synthesis of SBA-15 with addition of heptane, the obtained material shows the morphology that consisted of both silica sheets and coarse silica foam [68].

In the abovementioned synthesis of MSM with the addition of straight-chain alkanes, highly ordered mesostructure with 2D hexagonal symmetry $(\mathrm{p} 6 \mathrm{~mm})$, is common. However, one exception with the use of octane as swelling agent was also reported [43]. The octane-P123-water synthetic system results in novel silica particles in size of $100-200 \mathrm{~nm}$ long and 50-80 nm wide. Each particle contains some silica nanotubes arranged parallel in the way close to the minimum requirement for hexagonal structures. The pore size of such silica particles is around $13 \mathrm{~nm}$ due to the swelling effect of octane in P123 micelles. No possible route of the formation of such mesoporous silica material was proposed.

Hexane, octane, decane, dodecane, and hexadecane were used as pore-expanding agents in the synthetic system of alkan-ethanol-CTAB-water- $\mathrm{NH}_{4} \mathrm{OH}$ [69]. The pore size can range from 2.5 to $6.0 \mathrm{~nm}$, while decane was found to be the most effective pore expander [69]. Due to very low concentration of alkane in this synthetic system, different straightchain alkanes did not result in much different morphology of obtained mesoporous silica materials. All these mesoporous silica materials consist of independent nanoparticles in the size of the range from $40 \mathrm{~nm}$ to $100 \mathrm{~nm}$ with irregular shape. The addition of alkane also results in some loss of the order of mesoporous silica materials.

\subsection{Synthesis with the Separation of Alkane-Rich and Water-} Rich Phases. In the alkane-assisted synthesis of mesoporous silica materials, the pore size and morphology of obtained silica materials follow the amount of alkane. Generally, the pore size increases with amount of alkane until a saturation value, beyond which further increasing amount of alkane can hardly affect the pore size. When the amount alkane is lower than the saturation value in surfactant micelles, the alkane mainly acts as swelling agents. The formation of emulsion or microemulsion will be most possible if the amount of alkane is higher than its saturation value in surfactant micelles $[63,70-79]$ and then leads to the hierarchical structures in micrometer of nanometer scale. Then, the droplets of alkanesurfactant-water microemulsion will lead to great change of morphology. Johansson et al. used $n$-heptane as prepared large pore SBA-15 and found that the sheets of obtained SBA-15 are fragments of the spheres with a diameter more than $20 \mu \mathrm{m}$ and a sheet thickness of $\sim 400 \mathrm{~nm}$, reflecting the existence of emulsion droplets during synthesis and the channel length of SBA- 15 around $400 \mathrm{~nm}[80,81]$. The same group also employed the same strategy to prepare SBA-16 with expanded mesopores in the walls of the hollow spheres with a diameter of 10 to $30 \mu \mathrm{m}$ [82]. The hexagonally ordered pore structure can be maintained only for very low TMB/P123 molar ratio but a MCF mesoporous silica will be obtained upon increasing TMB/P123 ratio [70, 71]. When TIPB was used as swelling agent, the obtained silica material changes from hexagonally ordered structure for low TIPB/P123 ratio to a vesicle-like structure for high TIPB/P123 ratio [83].

The formation of microemulsion can be avoided by adding alkanes after silica source and the formation of embryonic mesoporous silica [84]. In the synthetic processes reported by Sun et al. [37, 43, 55, 56] and Zhang et al. [51] (see Section 2.1.2), alkanes were premixed with silica source and then added into reaction mixture with one exception, in which decane was added into $\mathrm{P} 123-\mathrm{HCl}$ solution before the addition of TEOS [34]. The formation of microemulsion can be possibly depressed in these cases [37, 43, 51, 55, 56]. However, the separation of alkane-rich phase and waterrich phase is inevitable when the amount of alkane is much higher than its solubilization capacity (saturation value) in surfactant micelles. Such separation of oil-phase and waterphase will inevitably result in irregular silica particles and the loss of highly ordered mesostructure.

Zhang et al. synthesized SBA-15 type mesoporous silica with $n$-decane as swelling agent in consideration of the fact that the excess amount of $n$-decane results in a separation of alkane-rich and water-rich layers after the addition of $n$-decane into $\mathrm{P} 123-\mathrm{H}_{2} \mathrm{O}$ solution [52]. The amount (the typical decane/P123 molar ratio was 310 ) of added $n$-decane was much higher than its saturation value in P123 micelles [54]. Consequently, a clear separation of decane-P123-water mixture to form an upper alkane-rich layer and a water-rich layer can be observed after stopping stirring (Figure 7(e)). A clear water-rich layer can be obtained after the removal of the upper alkane-rich layer (Figure 7(i)). Then, the silica source TEOS was added in the remaining water-rich layer to complete the synthesis of MSM. In such a synthetic process, highly ordered SBA- 15 type mesoporous silica materials can be obtained with the help of $\mathrm{NH}_{4} \mathrm{~F}$. As we can see in Figure 7, different straight-chain alkanes such as $n$-hexane, $n$-heptane, $n$-octane, $n$-nonane, $n$-decane, $n$-undecane, $n$-dodecane, and $n$-bioctyl lead to the same phenomenon if they were put into the synthesis of MSM in a $\mathrm{P} 123-\mathrm{H}_{2} \mathrm{O}$ system. These different straight-chain alkanes can lead the MSM materials with different pore structures and morphologies $[52,53]$. If the separation of such alkane-P123-water mixtures or the removal of upper alkane-rich layer is omitted, only smashed hollow silica spheres in scattered scales can be achieved. This is different from the results achieved by Sun et al. [37, 43, 55, 56], Tian et al. [85], and Zhang et al. [34, 51], who did not observe any phase separation of alkane- $\mathrm{P} 123-\mathrm{H}_{2} \mathrm{O}$ mixture to form upper alkane-rich layer and water-rich layer like that in Figure 7.

With the decane/P123 molar ratio ranging from 310 to 119 , hexagonally ordered SBA-15 type mesoporous silica can be obtained with a TEOS/P123 molar ratio of 41.4. The decane/P123 ratio at 119 needs an increased TEOS/P123 ratio at 59.6 to ensure the formation of hexagonally ordered SBA15 type mesoporous silica. The pore size of the obtained mesoporous silica materials is around $12.2 \mathrm{~nm}$, which is obviously larger than that of conventional SBA-15 type silica but smaller than that reported by Zhang et al. and Sun et al. using $n$-decane as swelling agent $[34,55,56]$. The changes of decane/P123 ratio and TEOS/P123 ratio just make the pore 

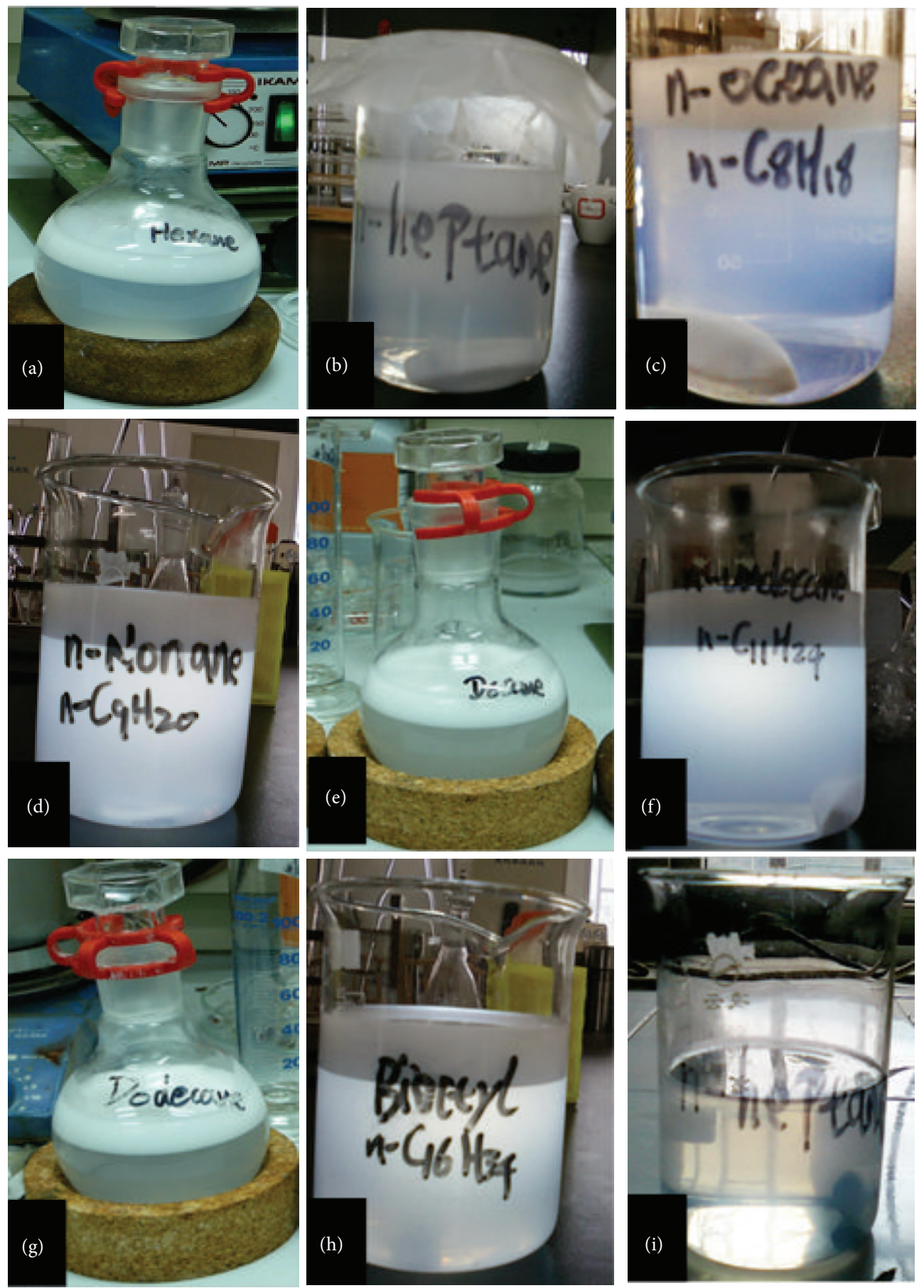

FiguRE 7: Phase separation of alkane-P123- $\mathrm{H}_{2} \mathrm{O}$ mixture to form upper alkane-rich layer and water-rich layer: (a) $n$-hexane; (b) $n$-heptane; (c) n-octane; (d) n-nonane; (e) $n$-decane; (f) n-undecane; (g) $n$-dodecane; (h) $n$-bioctyl; (i) the upper alkane-rich layer removed heptane$\mathrm{P} 123-\mathrm{H}_{2} \mathrm{O}$ mixture.

size of final products vary in a narrow range, reflecting that the solubilized decane in P123 micelles that had reached its saturation value.

The TEM images indicate that these SBA-15 type silica particles have hexagonally ordered nanochannels about $400 \mathrm{~nm}$ long. These hexagonally ordered nanochannels are along the direction vertical so that the particles grow.
Additionally, the alternating protuberant and hollow parts are partially a replica of these hexagonally ordered channels along the direction where those particles grow. The 3D tomography scan (Figure 8) indicates that the morphology of the obtained mesoporous silica is hierarchical 3D cocoon-like pouches with the wall constructed by hexagonally ordered nanochannels, which are characterized by their p6 $\mathrm{mm}$ 


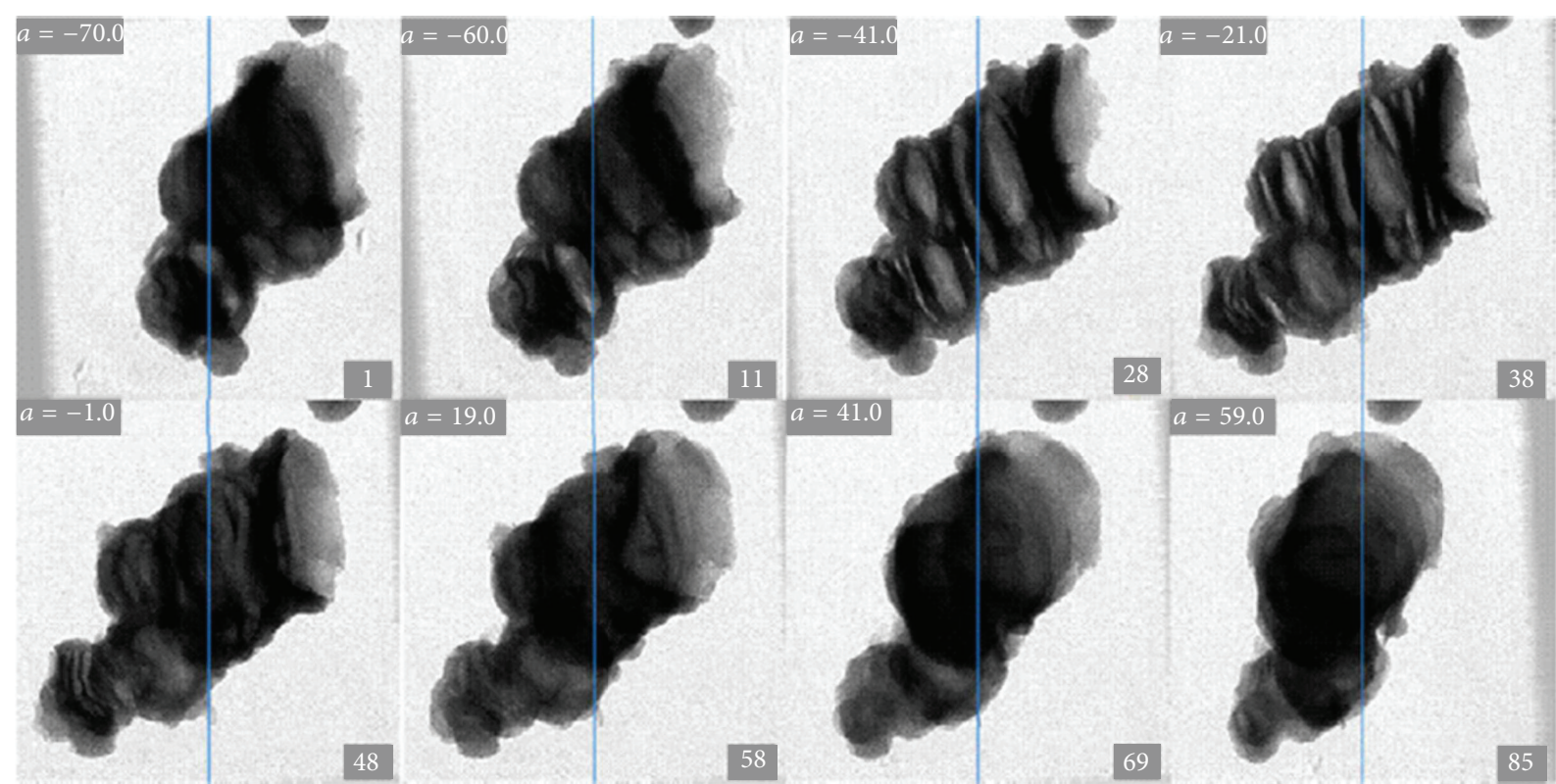

(a)

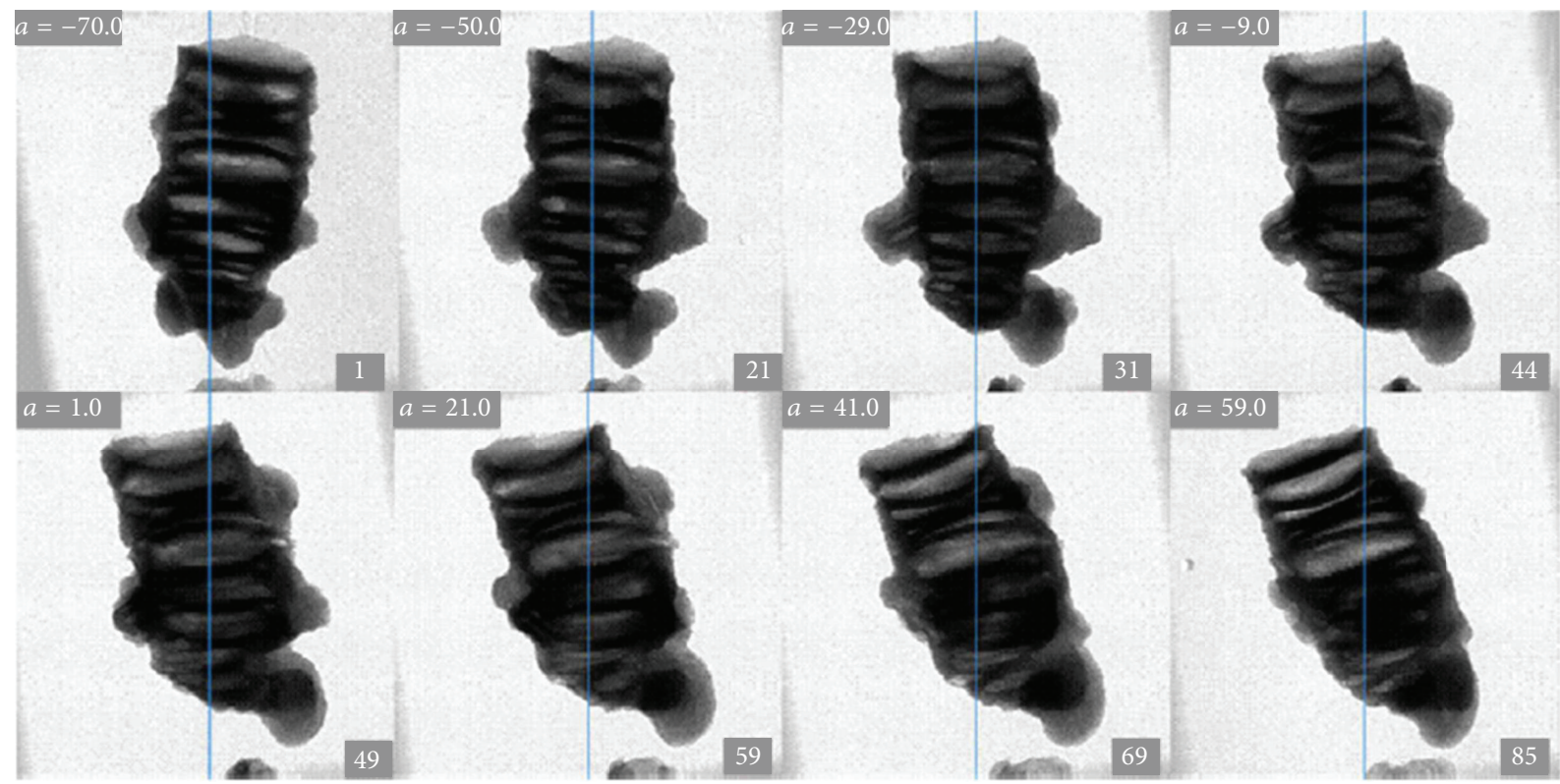

(b)

FIGURE 8: A sequence of TEM images obtained in 3-dimensional tomography scans along the axis (a) perpendicular and (b) parallel to the long axis of a particle of the material prepared at a decane/P123 molar ratio of 310 and a TEOS/P123 molar ratio of 41.4 . Reprinted with permission from [52]. Copyright (2012) Elsevier.

symmetry of SBA-15 type mesoporous silica. Then, the channel length of these particles is decided by the size of these $3 \mathrm{D}$ cocoon-like pouches and is around $200-400 \mathrm{~nm}$. One side of these cocoon-like pouches is open, implying possible application of this material in drug delivery, separation, adsorption, nanoreactor, and so forth [86].

The mechanism for the formation of this cocoon-like pouches was suggested to be an oil-in-water $(\mathrm{O} / \mathrm{W})$ emulsion assisted process [52]. In such oil-in-water emulsion assisted process, the residual $n$-decane in the water-rich layer plays two roles. The first one is to act as the swelling agent leading to enlarged pore size of obtained mesoporous silica. Meanwhile, the residual $n$-decane in the water-rich layer enables the formation of $\mathrm{O} / \mathrm{W}$ emulsion. The droplets of such $\mathrm{O} / \mathrm{W}$ emulsion present in the synthetic system and the crystallites of embryonic silica particle prefer to attach to the outside of these droplets. The attachment of these crystallites to $\mathrm{O} / \mathrm{W}$ emulsion droplets is energetically more favorable to other crystallites in an end-to-end way. However, the O/W emulsion droplets can aggregate in the hydrolysis process and 


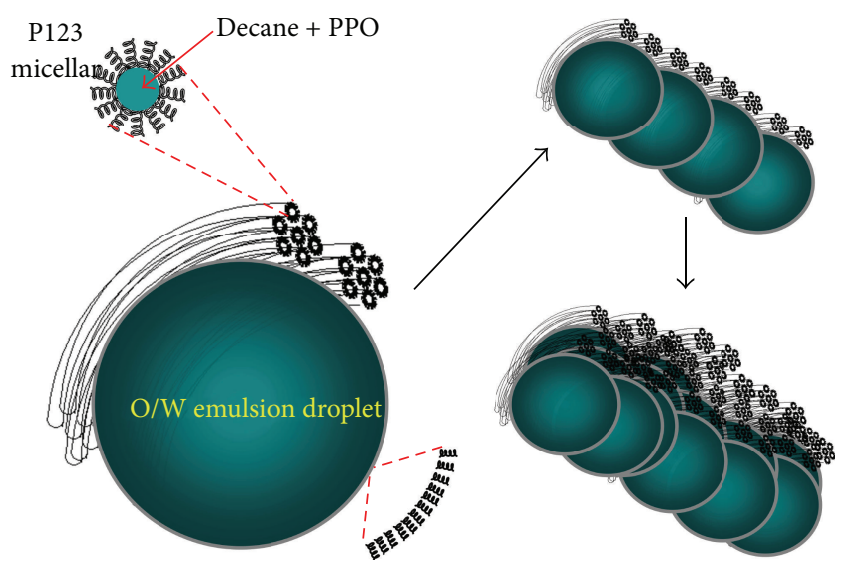

P123 monolayer

FIGURE 9: Schematic illustration of the motif of $\mathrm{O} / \mathrm{W}$ emulsion assisted process. Reprinted with permission from [52]. Copyright (2012) Elsevier.

hydrothermal process and then build in cocoon-like pouches, whose walls are constructed by highly ordered hexagonal channels of SBA-15 type silica materials. If stirring is stopped as soon as the white precipitation appears after the addition of TEOS [52, 87-89], neither hexagonally ordered mesostructure nor cocoon-like morphology but onion-like or cracked onion-like silica spheres with some parallel nanochannels along them were obtained [52], reflecting the formation of $\mathrm{O} / \mathrm{W}$ emulsion in this synthetic system. These onion-like silica spheres are composed of aggregated nanochannels $100-$ $200 \mathrm{~nm}$ long, which is very close to the channel length of these cocoon-like pouches. These onion-like silica spheres are embryonic patterns of final products. According to this mechanism, the channel length of obtained MSM is decided by the diameter of $\mathrm{O} / \mathrm{W}$ emulsion droplets. This mechanism (see Figure 9) is also reflected by the other synthesis of MSM with emulsion templating and characterized by the hierarchical hollow spherical morphologies of obtained MSM $[68,80-82,90,91]$.

In Figure 7, the $n$-hexane-P123-water and $n$-dodecaneP123-water systems also show the phase separation to form upper alkane-rich layer and water-rich layer below. With the removal of upper alkane-rich layer prior to the addition of TEOS, only $n$-decane-P123-water system can result in the formation of hexagonally ordered MSM [53]. The $n$-hexaneP123-water system leads to the formation of MCF material, which has typical MCF morphology and mesostructure as that of the MCF materials prepared with TMB [9] or TIPB $[41,42,58,67]$. However, the pore size of such MCF material prepared with $n$-hexane is around $10 \mathrm{~nm}$, much different from that of the MCF materials prepared with TMB or TIPB. The small pore size of the MCF material should be due to the smaller molecular size of $n$-hexane than that of TMB or TIPB. The $n$-dodecane-P123-water system results in a nanosized fiber-like MSM, which is composed of silica nanotube bundles. These nanotube bundles contain just several nanotube channels arranged parallel in one unit. The pore sizes of the
MSM prepared with $n$-hexane, $n$-decane, and $n$-dodecane vary from $10 \mathrm{~nm}$ ( $n$-hexane) to $11 \mathrm{~nm}$ ( $n$-dodecane) and $12 \mathrm{~nm}$ ( $n$-decane), indicating that the swelling effects of these straight-chain alkanes are comparable although the chain length and molecule size of them are remarkably different.

In the syntheses assisted by $n$-hexane, $n$-decane, and $n$ dodecane, the molecular ratios of alkane/P123 and TEOS/ P123 were all calculated by the amount of alkane, and P123 and TEOS were added into the system $[52,53]$. The removed upper alkane-rich layer also contains P123 and water in addition to alkane and thus the ratios of alkane/P123 in the residual water-rich layers are different from the original ones.

The pore expanding effect of decane in the synthesis of MSM templated by other nonionic gemini surfactant (E900Myr) under neural $\mathrm{pH}$ was also studied [45]. Upon addition of decane the hexagonal structure was kept as far the concentration of oil remained lower than $10 \mathrm{wt} \%$. If the hydrothermal treatment was carried out at low temperature of $50^{\circ} \mathrm{C}$, a slight increase of the mesopore diameter was observed in the presence of decane. Increasing the temperature up to $80^{\circ} \mathrm{C}$, the mean pore diameter decreases, in contrary to pore expanding upon the addition of decane. At the same time, better mesopore homogeneity and a larger wall thickness can be obtained. At high decane concentration, the oil-in-water emulsions formed by E900Myr/decane/water system could be used as template for the formation of hierarchical porous silica materials, which is quite different from the effect of increasing alkane/P123 molar ratio discovered by Sun et al. $[37,43,55,56]$ and Zhang et al. [34, 51]. Notably, the amount of ethanol can determine the pore size and the construction of pore structure while the concentration of $\mathrm{NH}_{4} \mathrm{OH}$ can directly influence and control the condensation rate of silica source and leads to different mesostructures.

\section{The Application of the Mesoporous Silica Synthesized with Straight-Chain Alkanes}

Since the invention of MSM such as MCM-41 and SBA-15, their application in abundant fields has been widely proposed and developed due to the potentiality to achieve a so-called nanoeffect in their nanochannels [75, 92-94]. Janssen et al. used 3D-TEM to study the shape of SBA-15 and found that the conventional SBA-15 MSM is composed of long and curved mesopores, which is not favorable to its application in many fields [95]. TMB [9, 10, 29-32], TIPB, and cyclohexane [28, $40-42,96]$ were used by many scientists as pore expanders to achieve big pore size but these swelling agents can also remarkably change the mesostructures and morphologies of obtained MSM materials. More importantly, these branchchain alkanes like TMB and TIPB normally exhibit very good pore expanding effect due to their relatively big molecular size, but this also means that they can hardly lead to a mesopore in a medium size. The use of TMB or TIPB as swelling agent can lead to a mesocellular foam silica (MCFs) with pore size as big as $30-50 \mathrm{~nm}$ but cannot lead to a MCFs with pore size as narrow as $10 \mathrm{~nm}[10,29-31,97]$. The use of $n$-hexane as swelling agent with a phase separation of hexane- $\mathrm{P} 123-\mathrm{H}_{2} \mathrm{O}$ mixture and the removal of upper hexanerich layer results in a MCFs material with mesopores as 
big as only $10 \mathrm{~nm}$ [53]. The straight-chain alkenes assisted synthetic systems make it possible to develop unconventional mesoporous silica materials with the characteristics like enlarged pore size, short channel length, and hierarchically constructed mesostructure and then remarkably enhance the application of mesoporous silica materials in different fields.

3.1. Adsorption and Separation. In chromatographic separation, using MSM as stationary phases, pore size is requested to be larger than $4 \mathrm{~nm}$ to expand their application in the chromatographic separation of biomolecules and aromatic molecules. The SBA-15 type MSM prepared using a synthetic system of decane-P123-water-TEOS exhibits a pore size of $12 \mathrm{~nm}$ as well as an average particle size of $400 \mathrm{~nm}$ [85]. The C18 derivative of this unconventional SBA-15 type MSM was packed into $50 \mu \mathrm{m}$ capillary for the application of capillary electrochromatography (CEC). Such material was found to be effective packing material for CEC application in either normal-phase or reverse-phase mode. In the normal-phase mode, high efficiency can be achieved for the separation of polar solutes due to the submicrometer particle size. In reverse-phase mode, high-speed separation of neutral and basic compounds can be achieved in $60 \mathrm{~s}$.

Using the abovementioned pore-expanded MSM as support materials $[69,98]$, a model enzyme (Lysozyme) was introduced into the tunable nanopores of these nanoparticles. It was found that the pore-expanded silica shows larger adsorption capacity than the conventional mesoporous silica with pore size of $2.5 \mathrm{~nm}$. The channel length of these poreexpanded mesoporous silica nanoparticles is less than $100 \mathrm{~nm}$ and these materials exhibit good potential to be a suitable carrier for enzyme delivery in the future [69]. The SBA-15 type material with an enlarged pore size of $12.0 \mathrm{~nm}$ shows higher adsorption capacity of lysozyme of $420.8 \mathrm{mg} \mathrm{g}^{-1}$, in contrast to $63.8 \mathrm{mg} \mathrm{g}^{-1}$ for a MCM-41 type material with a pore size of $2.05 \mathrm{~nm}$ and $191.3 \mathrm{mg} \mathrm{g}^{-1}$ for a conventional SBA15 type material with a pore size of $8.45 \mathrm{~nm}$ [99]. The reason for the high adsorption capacity of the SBA-15 materials is that the size of lysozyme is larger than MCM-41 pores but well suits the pore size of SBA-15 materials. A SBA15 material was synthesized with the assistance of octane and employed for adsorption of biomolecules and showed the highest maximum adsorption capacity of bovine serum albumin (BSA) and lysozyme (LYS) [100].

The platelet-like SBA-15 type silica prepared with $n$ decane was modified by amine and employed in the adsorption of $\mathrm{CO}_{2}[61,101]$. Besides the pore size and pore volume, the channel length of mesoporous silica plays a significant role in the performance of supported polyethylenimine (PEI) for $\mathrm{CO}_{2}$ adsorption. The short channel SBA-15 silica prepared with $n$-decane was found to be a much better support for PEI and $\mathrm{CO}_{2}$ uptake at low temperature due to diminished diffusion. In the adsorption of acid dyes, the short channeling pores of the amino-functionalized SBA- 15 platelets facilitated the diffusion of dye molecules inside the pores and prevented the aggregation of dye molecules from the blocking of the pores [102]. However, the adsorption capacity is dependent on the amount of amino-loading and surface area of the SBA-15 materials. Another thing that needs to be noticed is that the adsorption of volatile organic compounds (VOCs) such as toluene and benzene with MSM materials is probably not favored by short channel but long nanochannel of conventional fiber-like SBA-15 [103].

3.2. Hard Template. The mesoporous silica materials obtained in the straight-chain assisted system can be used as hard templates for the preparation of other mesoporous materials $[104,105]$. The assistance of $n$-hexane leads to formation of a macromesoporous silica material, which was used as the hard template for the preparation of hierarchically ordered macromesoporous carbon materials [106].

3.3. Catalysis. The MSM materials obtained in straight-chain alkanes assisted synthesis can offer short-length mesopores, which can lead to easy mass transfer in both biomolecule absorption and the facile assembly of metal nanocomposites within their pore channels $[107,108]$.

The abovementioned SBA- 15 type mesoporous silica [52, 53] prepared with the assistance of $n$-decane was employed as the support material of immobilized chiral Mn(salen) catalyst for the heterogeneous asymmetric epoxidation of unfunctionalized olefins [109]. Motion restriction and confinement effect in the nanochannels of support materials can affect the cis/trans ratio and enantioselectivity of obtained chiral epoxides. In the nanochannels of mesoporous silica with tunable pore dimension and channel length, motion restriction and confinement effect can be tuned and thus the product distribution of heterogeneous asymmetric epoxidation can be adjusted sequentially.

Decane and dodecane were used as swelling agents to prepare the SBA-15 type mesoporous silica materials with enlarged pore size (around $11 \mathrm{~nm}$ ) and short channel length (300-500 nm) [110]. The impact of channel length on metal dispersion and the catalytic performance of Ru-Co/SBA-15 catalysts in Fischer-Tropsch synthesis had been investigated. The long channel length (up to $10 \mu \mathrm{m}$ ) and corresponding long channel-residence time for conventional SBA-15 promote the formation of highly aggregated rod-like $\mathrm{CO}_{3} \mathrm{O}_{4}$ particles. The short channel SBA-15 silicas were found to be able to greatly enhance the dispersion of metal active species. The high dispersion of metal active species leads to a higher Co-time-yield under realistic Fischer-Tropsch conditions. At $55 \%$ CO conversion level, the selectivity to desired C5+ fraction progressively increases when the channel length of the SBA-15 support is gradually shortened. The design of Fischer-Tropsch catalysts on the short channel SBA-15 silica with large pore size was suggested to be a successful strategy toward improved catalytic activity and $\mathrm{C} 5+$ hydrocarbon selectivity.

In the oxidative removal of 4,6-dimethyldibenzothiophene (4.6-DMDBT), Sun et al. found that the catalytic performance of Ti-HMS molecular sieve can be remarkably enhanced while its pore size was expanded from $2.3 \mathrm{~nm}$ to $3.7 \mathrm{~nm}$ with the addition of $n$-hexane or $n$-octane in its preparation [57]. However, the effect of the addition $n$-hexane or $n$-octane on the morphology of obtained Ti-HMS material was absent. 


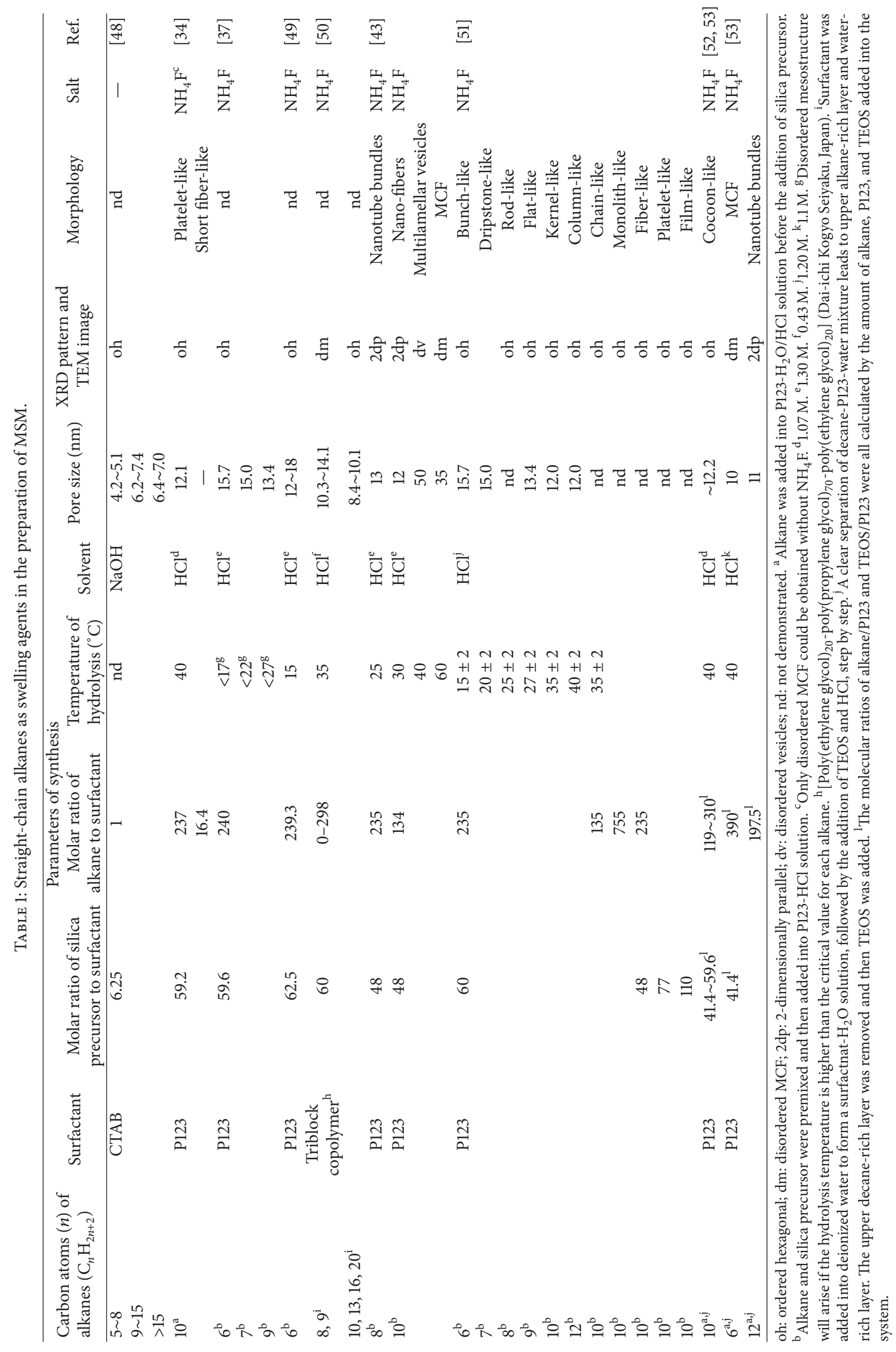


A SBA-15 material prepared with the assistance of $n$ decane demonstrates appropriate channel size $(14.0 \mathrm{~nm})$ and best capacity of lipase. The immobilized catalyst with this SBA-15 material shows much higher activity and sustainability of activity than the immobilized catalysts with a MCM-41 material (channel size $1.8 \mathrm{~nm}$ ) and a MCF material (channel size $28.0 \mathrm{~nm}$ ) as support materials in the transformation of unrefined wasted cooking oil to biodiesel [111].

$n$-Hexane was used as swelling agent for the preparation of variable pore diameter SBA-15 materials and [39]. The SBA15 supported catalyst with pore diameter of $10 \mathrm{~nm}$ sufficient mass transfer of reactant liquids and gases through the catalyst's pores while still maintaining a high surface area necessary for metal dispersion.

\section{Conclusions}

It is possible to tune the mesostructure and morphology of MSM by controlling the type and amount of surfactant and silica source and other synthesis parameters, that is, temperature, inorganic mineralizing agent, and the way to introduce the swelling agent into reaction mixture. Acting as swelling agents, straight-chain alkanes $\left(\mathrm{C}_{n} \mathrm{H}_{2 n+2}, n=5\right.$ to 20$)$ have been widely used in the synthetic systems of $\mathrm{C}_{n} \mathrm{H}_{2 n+2^{-}}$ surfactant-water- $\mathrm{SiO}_{2}$ (see Table 1), which play a critical role in fabrication of MSM with tunable pore diameter, channel length, and specific morphology. The MSM prepared with the assistance of straight-chain alkanes is characterized by enlarged pore diameter, short channel length, and hierarchically constructed mesostructure. Their application indicates that the exploitation of these unconventional mesoporous silica materials is a prospectively successful strategy in the fields, for example, catalysis, adsorption, separation, and nanomaterial preparation.

\section{Conflict of Interests}

The authors declare that there is no conflict of interests regarding the publication of this paper.

\section{Acknowledgments}

The authors are grateful for National Natural Science Foundation of China (Grants nos. U1362105 and 21273076), Chongqing Research Program of Basic Research and Frontier Technology (nos. cstc2013jcyjA50007 and cstc2015shmsztzx20001), Chongqing Science Research Project (KJ130729), and Key Laboratory of Catalysis Science and Technology of Chongqing Education Commission (1456031).

\section{References}

[1] Y. Wan and D. Y. Zhao, "On the controllable soft-templating approach to mesoporous silicates," Chemical Reviews, vol. 107, no. 7, pp. 2821-2860, 2007.

[2] J. S. Beck, J. C. Vartuli, G. J. Kennedy, C. T. Kresge, W. J. Roth, and S. E. Schramm, "Molecular or supramolecular templating: defining the role of surfactant chemistry in the formation of microporous and mesoporous molecular sieves," Chemistry of Materials, vol. 6, no. 10, pp. 1816-1821, 1994.
[3] J. S. Beck, J. C. Vartuli, W. J. Roth et al., "A new family of mesoporous molecular sieves prepared with liquid crystal templates," Journal of the American Chemical Society, vol. 114, no. 27, pp. 10834-10843, 1992.

[4] C. T. Kresge, M. E. Leonowicz, W. J. Roth, J. C. Vartuli, and J. S. Beck, "Ordered mesoporous molecular sieves synthesized by a liquid-crystal template mechanism," Nature, vol. 359, no. 6397, pp. 710-712, 1992.

[5] J. C. Vartuli, K. D. Schmitt, C. T. Kresge et al., "Effect of surfactant silica molar ratios on the formation of mesoporous molecular-sieves-inorganic mimicry of surfactant liquid-crystal phase and mechnistic implications," Chemistry of Materials, vol. 6, pp. 2317-2326, 1994.

[6] W. J. Roth and J. C. Vartuli, "Synthesis of mesoporous molecular sieves," in Zeolites and Ordered Mesoporous Materials: Progress and Prospects, J. Cejka and H. VanBekkum, Eds., vol. 157 of Studies in Surface Science and Catalysis, pp. 91-110, Elsevier Science Bv, Amsterdam, The Netherlands, 2005.

[7] J. S. Beck and J. C. Vartuli, "Recent advances in the synthesis, characterization and applications of mesoporous molecular sieves," Current Opinion in Solid State and Materials Science, vol. 1, no. 1, pp. 76-87, 1996.

[8] Q. S. Huo, D. I. Margolese, U. Ciesla et al., "Generalized synthesis of periodic surfactant inorganic composite-materials," Nature, vol. 368, no. 6469, pp. 317-321, 1994.

[9] D. Y. Zhao, Q. S. Huo, J. L. Feng, B. F. Chmelka, and G. D. Stucky, "Nonionic triblock and star diblock copolymer and oligomeric sufactant syntheses of highly ordered, hydrothermally stable, mesoporous silica structures," Journal of the American Chemical Society, vol. 120, no. 24, pp. 6024-6036, 1998.

[10] D. Y. Zhao, J. L. Feng, Q. S. Huo et al., “Triblock copolymer syntheses of mesoporous silica with periodic 50 to 300 angstrom pores," Science, vol. 279, no. 5350, pp. 548-552, 1998.

[11] F. Kleitz, T. Czuryszkiewicz, L. A. Solovyov, and M. Lindén, "Xray structural modeling and gas adsorption analysis of cagelike SBA-16 silica mesophases prepared in a F127/butanol/ $\mathrm{H}_{2} \mathrm{O}$ system," Chemistry of Materials, vol. 18, no. 21, pp. 5070-5079, 2006.

[12] J. C. Vartuli, K. D. Schmitt, C. T. Kresge et al., "Development of a formation mechanism for M41S materials," Studies in Surface Science and Catalysis, vol. 84, pp. 53-60, 1994.

[13] A. A. Romero, M. D. Alba, W. Z. Zhou, and J. Klinowski, "Synthesis and characterization of the mesoporous silicate molecular sieve MCM-48," Journal of Physical Chemistry B, vol. 101, no. 27, pp. 5294-5300, 1997.

[14] M. W. Anderson, "Simplified description of MCM-48," Zeolites, vol. 19, no. 4, pp. 220-227, 1997.

[15] S. A. Bagshaw, E. Prouzet, and T. J. Pinnavaia, “Templating of mesoporous molecular sieves by nonionic polyethylene oxide surfactants," Science, vol. 269, no. 5228, pp. 1242-1244, 1995.

[16] H. D. Zhang, L. Zhang, Z. C. Feng et al., "Selective oxidation of methane to formaldehyde over MSU-2-supported Sb-V mixed oxide catalyst," Chinese Journal of Catalysis, vol. 26, no. 7, pp. 542-544, 2005.

[17] C. Boissiere, A. Larbot, A. van der Lee, P. J. Kooyman, and E. Prouzet, "A new synthesis of mesoporous MSU-X silica controlled by a two-step pathway," Chemistry of Materials, vol. 12, no. 10, pp. 2902-2913, 2000.

[18] S. A. Bagshaw, "Modification of [M]-MSU-X mesoporous silicate pore morphology by post-synthesis treatment," Chemical Communications, no. 3, pp. 271-272, 1999. 
[19] A. B. Chen, Y. F. Yu, H. J. Lv, Y. Zhang, T. T. Xing, and Y. H. Yu, "Synthesis of hollow mesoporous silica spheres and carambolalike silica materials with a novel resin sphere as template," Materials Letters, vol. 135, pp. 43-46, 2014.

[20] B. Liu, L. Han, and S. A. Che, "Formation of enantiomeric impeller-like helical architecures by DNA self-assembly and silica mineralization," Angewandte Chemie: International Edition, vol. 51, no. 4, pp. 923-927, 2012.

[21] D. Y. Zhao, J. Y. Sun, Q. Z. Li, and G. D. Stucky, "Morphological control of highly ordered mesoporous silica SBA-15," Chemistry of Materials, vol. 12, no. 2, pp. 275-279, 2000.

[22] A. S. M. Chong and X. S. Zhao, "Functionalization of SBA-15 with APTES and characterization of functionalized materials," Journal of Physical Chemistry B, vol. 107, no. 46, pp. 12650-12657, 2003.

[23] H. B. S. Chan, P. M. Budd, and T. D. Naylor, "Control of mesostructured silica particle morphology," Journal of Materials Chemistry, vol. 11, no. 3, pp. 951-957, 2001.

[24] B. Z. Li, X. F. Pei, S. B. Wang et al., "Formation of hollow mesoporous silica nanoworm with two holes at the terminals," Nanotechnology, vol. 21, no. 2, Article ID 025601, 2010.

[25] Y. L. Chen, Y. X. Chen, Y. Li et al., "Preparation of ethenylenesilica hollow spheres with a single-layer mesopores using a chiral amphiphile," Journal of Nanoscience and Nanotechnology, vol. 11, no. 5, pp. 4073-4078, 2011.

[26] Y. L. Chen, Y. Li, W. Zhuang et al., "Formation of silica nanotubes with spring-like pore channels in the walls," Materials Chemistry and Physics, vol. 127, no. 3, pp. 426-432, 2011.

[27] S. Yang, X. Zhou, P. Yuan et al., "Siliceous nanopods from a compromised dual-templating approach," Angewandte ChemieInternational Edition, vol. 46, no. 45, pp. 8579-8582, 2007.

[28] M. Kruk, "Access to ultralarge-pore ordered mesoporous materials through selection of surfactant/swelling-agent micellar templates," Accounts of Chemical Research, vol. 45, no. 10, pp. 1678-1687, 2012.

[29] P. Schmidt-Winkel, J. W. W. Lukens, D. Y. Zhao, P. D. Yang, B. F. Chmelka, and G. D. Stucky, "Mesocellular siliceous foams with uniformly sized cells and windows," Journal of the American Chemical Society, vol. 121, no. 1, pp. 254-255, 1999.

[30] J. J. Ma, Q. M. Liu, D. D. Chen, S. Wen, and T. H. Wang, "Synthesis and characterization of pore-expanded mesoporous silica materials," Micro \& Nano Letters, vol. 10, no. 2, pp. 140-144, 2015.

[31] J. L. Blin and B. L. Su, "Tailoring pore size of ordered mesoporous silicas using one or two organic auxiliaries as expanders," Langmuir, vol. 18, no. 13, pp. 5303-5308, 2002.

[32] C. L. Xin, N. Zhao, H. J. Zhan, F. K. Xiao, W. Wei, and Y. H. Sun, "Phase transition of silica in the TMB-P123- $\mathrm{H}_{2} \mathrm{O}-\mathrm{TEOS}$ quadru-component system: a feasible route to different mesostructured materials," Journal of Colloid and Interface Science, vol. 433, pp. 176-182, 2014.

[33] L. Huang and M. Kruk, "Synthesis of ultra-large-pore FDU-12 silica using ethylbenzene as micelle expander," Journal of Colloid and Interface Science, vol. 365, no. 1, pp. 137-142, 2012.

[34] H. Zhang, J. M. Sun, D. Ma et al., "Unusual mesoporous SBA-15 with parallel channels running along the short axis," Journal of the American Chemical Society, vol. 126, no. 24, pp. 7440-7441, 2004.

[35] S. M. Egger, K. R. Hurley, A. Datt, G. Swindlehurst, and C. L. Haynes, "Ultraporous mesostructured silica nanoparticles," Chemistry of Materials, vol. 27, no. 9, pp. 3193-3196, 2015.
[36] J. L. Blin, C. Otjacques, G. Herrier, and B.-L. Su, "Pore size engineering of mesoporous silicas using decane as expander," Langmuir, vol. 16, no. 9, pp. 4229-4236, 2000.

[37] J. M. Sun, H. Zhang, D. Ma et al., "Alkanes-assisted low temperature formation of highly ordered SBA-15 with large cylindrical mesopores," Chemical Communications, no. 42, pp. 5343-5345, 2005.

[38] W. J. Shan, W. Wang, and H. Q. Ru, "Siliceous mesocellular foams modified via a partitioned cooperative self-assembly process using hexane as pore swelling agent," Journal of NonCrystalline Solids, vol. 425, pp. 183-189, 2015.

[39] P. E. Boahene, K. K. Soni, A. K. Dalai, and J. Adjaye, "Application of different pore diameter SBA-15 supports for heavy gas oil hydrotreatment using FeW catalyst," Applied Catalysis A: General, vol. 402, no. 1-2, pp. 31-40, 2011.

[40] Y. Y. Li and M. Kruk, "Single-micelle-templated synthesis of hollow silica nanospheres with tunable pore structures," RSC Advances, vol. 5, no. 85, pp. 69870-69877, 2015.

[41] L. Cao and M. Kruk, "Short synthesis of ordered silicas with very large mesopores," RSC Advances, vol. 4, no. 1, pp. 331-339, 2014.

[42] L. Cao and M. Kruk, "Synthesis of large-pore SBA-15 silica from tetramethyl orthosilicate using triisopropylbenzene as micelle expander," Colloids and Surfaces A: Physicochemical and Engineering Aspects, vol. 357, no. 1-3, pp. 91-96, 2010.

[43] J. M. Sun, H. Zhang, R. J. Tian et al., "Ultrafast enzyme immobilization over large-pore nanoscale mesoporous silica particles," Chemical Communications, no. 12, pp. 1322-1324, 2006.

[44] A. Sayari, Y. Yang, M. Kruk, and M. Jaroniec, "Expanding the pore size of MCM-41 silicas: use of amines as expanders in direct synthesis and postsynthesis procedures," Journal of Physical Chemistry B, vol. 103, no. 18, pp. 3651-3658, 1999.

[45] A. May-Masnou, A. Pasc, M. J. Stébé, J. M. Gutiérrez, M. Porras, and J. L. Blin, "Solubilization of decane into gemini surfactant with a modified Jeffamine backbone: design of hierarchical porous silica," Microporous \& Mesoporous Materials, vol. 169, pp. 235-241, 2013.

[46] Q. S. Huo, D. I. Margolese, U. Ciesla et al., "Organization of organic molecules with inorganic molecular species into nanocomposite biphase arrays," Chemistry of Materials, vol. 6, no. 8, pp. 1176-1191, 1994.

[47] J. Fan, C. Z. Yu, J. Lei et al., "Low-temperature strategy to synthesize highly ordered mesoporous silicas with very large pores," Journal of the American Chemical Society, vol. 127, no. 31, pp. 10794-10795, 2005.

[48] N. Ulagappan and C. N. R. Rao, "Evidence for supramolecular organization of alkane and surfactant molecules in the process of forming mesoporous silica," Chemical Communications, no. 24, pp. 2759-2760, 1996.

[49] M. Kruk and L. Cao, "Pore size tailoring in large-pore SBA-15 silica synthesized in the presence of hexane," Langmuir, vol. 23, no. 13, pp. 7247-7254, 2007.

[50] S. K. Jana, R. Nishida, K. Shindo, T. Kugita, and S. Namba, "Pore size control of mesoporous molecular sieves using different organic auxiliary chemicals," Microporous and Mesoporous Materials, vol. 68, no. 1-3, pp. 133-142, 2004.

[51] H. Zhang, J. M. Sun, D. Ma, G. Weinberg, D. S. Su, and X. K. Bao, "Engineered complex emulsion system: toward modulating the pore length and morphological architecture of mesoporous silicas," Journal of Physical Chemistry B, vol. 110, no. 51, pp. 25908-25915, 2006. 
[52] H. D. Zhang, Y.-M. Wang, K. Lü et al., "Hierarchical fabrication of silica cocoon with hexagonally ordered channel constructed wall via an emulsion-assisted process," Microporous and Mesoporous Materials, vol. 150, no. 1, pp. 90-95, 2012.

[53] H. D. Zhang and Y. Shen, "Straight chain alkane-assisted synthesis of mesoporous silica," Materials Letters, vol. 75, pp. 183$185,2012$.

[54] R. Nagarajan, "Solubilization of hydrocarbons and resulting aggregate shape transitions in aqueous solutions of Pluronic (PEO-PPO-PEO) block copolymers," Colloids and Surfaces B: Biointerfaces, vol. 16, no. 1-4, pp. 55-72, 1999.

[55] J. M. Sun, D. Ma, H. Zhang et al., "Organic molecule-modulated phase evolution of inorganic mesostructures," Langmuir, vol. 24, no. 6, pp. 2372-2380, 2008.

[56] J. M. Sun, D. Ma, H. Zhang et al., "Phase evolution in the alkane-P123-water-TEOS quadru-component system: a feasible route to different complex mesostructured materials," Journal of Materials Chemistry, vol. 16, no. 16, pp. 1507-1510, 2006.

[57] D. W. Sun, G. Li, C. Z. Jin, L. X. Zhao, and X. S. Wang, "Effect of straight chain alkanes on the synthesis of Ti-HMS molecular sieve," Chinese Journal of Catalysis, vol. 28, pp. 479-483, 2007.

[58] L. Cao and M. Kruk, "Facile method to synthesize platelet SBA15 silica with highly ordered large mesopores," Journal of Colloid and Interface Science, vol. 361, no. 2, pp. 472-476, 2011.

[59] Sujandi, S.-E. Park, D.-S. Han, S.-C. Han, M.-J. Jin, and T. Ohsuna, "Amino-functionalized SBA-15 type mesoporous silica having nanostructured hexagonal platelet morphology," Chemical Communications, no. 39, pp. 4131-4133, 2006.

[60] K. Kosuge, T. Sato, N. Kikukawa, and M. Takemori, "Morphological control of rod-and fiberlike SBA-15 type mesoporous silica using water-soluble sodium silicate," Chemistry of Materials, vol. 16, no. 5, pp. 899-905, 2004.

[61] A. Heydari-Gorji, Y. Yang, and A. Sayari, "Effect of the pore length on $\mathrm{CO}_{2}$ adsorption over amine-modified mesoporous silicas," Energy and Fuels, vol. 25, no. 9, pp. 4206-4210, 2011.

[62] K. Shinoda and S. Friberg, "Microemulsions: colloidal aspects," Advances in Colloid and Interface Science, vol. 4, no. 4, pp. 281300, 1975.

[63] A. Kabalnov, B. Lindman, U. Olsson, L. Piculell, K. Thuresson, and H. Wennerström, "Microemulsions in amphiphilic and polymer-surfactant systems," Colloid and Polymer Science, vol. 274, no. 4, pp. 297-308, 1996.

[64] P. D. I. Fletcher and K. Suhling, "Interactions between weakly charged oil-in-water microemulsion droplets," Langmuir, vol. 14, no. 15, pp. 4065-4069, 1998.

[65] M. J. Lawrence and G. D. Rees, "Microemulsion-based media as novel drug delivery systems," Advanced Drug Delivery Reviews, vol. 45, no. 1, pp. 89-121, 2000.

[66] M. Kobašlija and D. T. McQuade, "Polyurea microcapsules from oil-in-oil emulsions via interfacial polymerization," Macromolecules, vol. 39, no. 19, pp. 6371-6375, 2006.

[67] Y.-Y. Fahn, A.-C. Su, and P. Shen, "Towerlike SBA-15: base and (10)-specific coalescence of a silicate-encased hexagonal mesophase tailored by nonionic triblock copolymers," Langmuir, vol. 21, no. 1, pp. 431-436, 2005.

[68] E. M. Johansson, J. M. Córdoba, and M. Odén, "The effects on pore size and particle morphology of heptane additions to the synthesis of mesoporous silica SBA-15," Microporous and Mesoporous Materials, vol. 133, no. 1-3, pp. 66-74, 2010.

[69] K.-C. Kao and C.-Y. Mou, "Pore-expanded mesoporous silica nanoparticles with alkanes/ethanol as pore expanding agent," Microporous and Mesoporous Materials, vol. 169, pp. 7-15, 2013.
[70] P. Schmidt-Winkel, C. J. Glinka, and G. D. Stucky, "Microemulsion templates for mesoporous silica," Langmuir, vol. 16, no. 2, pp. 356-361, 2000.

[71] J. S. Lettow, Y. J. Han, P. Schmidt-Winkel et al., "Hexagonal to mesocellular foam phase transition in polymer-templated mesoporous silicas," Langmuir, vol. 16, no. 22, pp. 8291-8295, 2000.

[72] P. Schmidt-Winkel, W. W. Lukens Jr., P. D. Yang et al., "Microemulsion templating of siliceous mesostructured cellular foams with well-defined ultralarge mesopores," Chemistry of Materials, vol. 12, no. 3, pp. 686-696, 2000.

[73] S. Schacht, Q. Huo, I. G. Voigt-Martin, G. D. Stucky, and F. Schüth, "Oil-water interface templating of mesoporous macroscale structures," Science, vol. 273, no. 5276, pp. 768-771, 1996.

[74] M. H. Wang, Z. K. Sun, Q. Yue et al., "An interface-directed coassembly approach to synthesize uniform large-pore mesoporous silica spheres," Journal of the American Chemical Society, vol. 136, no. 5, pp. 1884-1892, 2014.

[75] M. Moritz and M. Geszke-Moritz, "Mesoporous materials as multifunctional tools in biosciences: principles and applications," Materials Science and Engineering C, vol. 49, pp. 114-151, 2015.

[76] S.-H. Wu, Y. Hung, and C.-Y. Mou, "Compartmentalized hollow silica nanospheres templated from nanoemulsions," Chemistry of Materials, vol. 25, no. 3, pp. 352-364, 2013.

[77] A. Lind, J. Andersson, S. Karlsson, M. Lindén, and J. B. Rosenholm, "Solubilization of benzene derivatives in silicatesurfactant systems," Colloids and Surfaces A: Physicochemical and Engineering Aspects, vol. 183, pp. 415-422, 2001.

[78] M. Lindén, P. Ågren, S. Karlsson, P. Bussain, and H. Amenitsch, "Solubilization of oil in silicate-surfactant mesostructures," Langmuir, vol. 16, no. 13, pp. 5831-5836, 2000.

[79] C. Oh, Y.-G. Lee, J.-H. Park, and S.-G. Oh, "Synthesis of silica microspheroids for templates in W/O reverse emulsion," Colloids and Surfaces A: Physicochemical and Engineering Aspects, vol. 269, no. 1-3, pp. 112-118, 2005.

[80] E. M. Johansson, J. M. Córdoba, and M. Odén, "Synthesis and characterization of large mesoporous silica SBA-15 sheets with ordered accessible $18 \mathrm{~nm}$ pores," Materials Letters, vol. 63, no. 24-25, pp. 2129-2131, 2009.

[81] E. M. Johansson, M. A. Ballem, J. M. Córdoba, and M. Odén, "Rapid synthesis of SBA-15 rods with variable lengths, widths, and tunable large pores," Langmuir, vol. 27, no. 8, pp. 49944999, 2011.

[82] M. A. Ballem, E. M. Johansson, J. M. Córdoba, and M. Odén, "Synthesis of hollow silica spheres SBA-16 with large-pore diameter," Materials Letters, vol. 65, no. 7, pp. 1066-1068, 2011.

[83] G. W. Zhou, Y. J. Chen, J. H. Yang, and S. H. J. Yang, "From cylindrical-channel mesoporous silica to vesicle-like silica with well-defined multilamella shells and large inter-shell mesopores," Journal of Materials Chemistry, vol. 17, no. 27, pp. 28392844, 2007.

[84] T. Lu, X. D. Yao, G. Q. M. Lu, and Y. H. He, "Controlled evolution from multilamellar vesicles to hexagonal mesostructures through the addition of 1,3,5-trimethylbenzene," Journal of Colloid and Interface Science, vol. 336, no. 1, pp. 368-373, 2009.

[85] R. J. Tian, J. M. Sun, H. Zhang et al., "Large-pore mesoporous SBA-15 silica particles with submicrometer size as stationary phases for high-speed CEC separation," Electrophoresis, vol. 27, no. 4, pp. 742-748, 2006. 
[86] Y. F. Zhu and J. L. Shi, "A mesoporous core-shell structure for $\mathrm{pH}$-controlled storage and release of water-soluble drug," Microporous and Mesoporous Materials, vol. 103, no. 1-3, pp. 243-249, 2007.

[87] D. C. Roux, J.-F. Berret, G. Porte, E. Peuvrel-Disdier, and P. Lindner, "Shear-induced orientations and textures of nematic wormlike micelles," Macromolecules, vol. 28, no. 5, pp. 1681$1687,1995$.

[88] H. W. Hillhouse, T. Okudo, J. W. van Egmond, and M. Tsapatsis, "Preparation of supported mesoporous silica layers in a continuous flow cell," Chemistry of Materials, vol. 9, no. 7, pp. 1505-1507, 1997.

[89] B. Tan, H.-J. Lehmler, S. M. Vyas, B. L. Knutson, and S. E. Rankin, "Fluorinated-surfactant-templated synthesis of hollow silica particles with a single layer of mesopores in their shells," Advanced Materials, vol. 17, no. 19, pp. 2368-2371, 2005.

[90] C. I. Zoldesi, C. A. Van Walree, and A. Imhof, "Deformable hollow hybrid silica/siloxane colloids by emulsion templating," Langmuir, vol. 22, no. 9, pp. 4343-4352, 2006.

[91] M. Fujiwara, K. Shiokawa, I. Sakakura, and Y. Nakahara, "Silica hollow spheres with nano-macroholes like diatomaceous earth," Nano Letters, vol. 6, no. 12, pp. 2925-2928, 2006.

[92] A. Corma, "From microporous to mesoporous molecular sieve materials and their use in catalysis," Chemical Reviews, vol. 97, no. 6, pp. 2373-2419, 1997.

[93] A. T. Bell, "The impact of nanoscience on heterogeneous catalysis," Science, vol. 299, no. 5613, pp. 1688-1691, 2003.

[94] N. Ž. Knežević and J.-O. Durand, "Large pore mesoporous silica nanomaterials for application in delivery of biomolecules," Nanoscale, vol. 7, no. 6, pp. 2199-2209, 2015.

[95] A. H. Janssen, P. van der Voort, A. J. Koster, and K. P. de Jong, "A 3D-TEM study of the shape of mesopores in SBA-15 and modified SBA-15 materials," Chemical Communications, vol. 15, pp. 1632-1633, 2002.

[96] L. Cao, T. Man, and M. Kruk, "Synthesis of ultra-large-pore SBA-15 silica with two-dimensional hexagonal structure using triisopropylbenzene as micelle expander," Chemistry of Materials, vol. 21, no. 6, pp. 1144-1153, 2009.

[97] T. P. B. Nguyen, J.-W. Lee, W. G. Shim, and H. Moon, "Synthesis of functionalized SBA-15 with ordered large pore size and its adsorption properties of BSA," Microporous and Mesoporous Materials, vol. 110, no. 2-3, pp. 560-569, 2008.

[98] D. I. Fried, F. J. Brieler, and M. Fröba, "Designing inorganic porous materials for enzyme adsorption and applications in biocatalysis," ChemCatChem, vol. 5, no. 4, pp. 862-884, 2013.

[99] R. J. Tian, H. Zhang, M. L. Ye et al., "Selective extraction of peptides from human plasma by highly ordered mesoporous silica particles for peptidome analysis," Angewandte ChemieInternational Edition, vol. 46, no. 6, pp. 962-965, 2007.

[100] S. M. L. dos Santos, K. A. B. Nogueira, M. D. S. Gama, J. D. F. Lima, I. J. da Silva Jr., and D. C. S. de Azevedo, "Synthesis and characterization of ordered mesoporous silica (SBA-15 and SBA-16) for adsorption of biomolecules," Microporous and Mesoporous Materials, vol. 180, pp. 284-292, 2013.

[101] L. Y. Zhou, J. Fan, G. K. Cui et al., "Highly efficient and reversible $\mathrm{CO}_{2}$ adsorption by amine-grafted platelet SBA-15 with expanded pore diameters and short mesochannels," Green Chemistry, vol. 16, no. 8, pp. 4009-4016, 2014.

[102] J. Lee, C. Chen, and S. Cheng, "Adsorption of acid dyes by functionalized SBA-15 mesoporous silica of different pore lengths," Journal of the Chinese Chemical Society, vol. 62, no. 6, pp. 483494, 2015.
[103] K. Kosuge, S. Kubo, N. Kikukawa, and M. Takemori, "Effect of pore structure in mesoporous silicas on VOC dynamic adsorption/desorption performance," Langmuir, vol. 23, no. 6, pp. 3095-3102, 2007.

[104] Y. T. Gong, Z. Z. Wei, J. Wang, P. F. Zhang, H. R. Li, and Y. Wang, "Design and fabrication of hierarchically porous carbon with a template-free method," Scientific Reports, vol. 4, article 6349, 2014.

[105] Z. X. Yan, H. Meng, L. Shi, Z. H. Li, and P. K. Shen, "Synthesis of mesoporous hollow carbon hemispheres as highly efficient Pd electrocatalyst support for ethanol oxidation," Electrochemistry Communications, vol. 12, no. 5, pp. 689-692, 2010.

[106] J. M. Sun, D. Ma, H. Zhang, X. H. Bao, G. Weinberg, and D. S. Su, "Macro-mesoporous silicas complex and the carbon replica," Microporous and Mesoporous Materials, vol. 100, no. 1-3, pp. 356-360, 2007.

[107] J. M. Sun and X. H. Bao, "Textural manipulation of mesoporous materials for hosting of metallic nanocatalysts," Chemistry-A European Journal, vol. 14, no. 25, pp. 7478-7488, 2008.

[108] E. Serrano, N. Linares, J. Garcia-Martinez, and J. R. Berenguer, "SolGel coordination chemistry: building catalysts from the bottom-up," ChemCatChem, vol. 5, no. 4, pp. 844-860, 2013.

[109] H. D. Zhang, Y.-M. Wang, L. Zhang et al., "Enantioselective epoxidation of $\beta$-methylstyrene catalyzed by immobilized $\mathrm{Mn}$ (salen) catalysts in different mesoporous silica supports," Journal of Catalysis, vol. 256, no. 2, pp. 226-236, 2008.

[110] G. Prieto, A. Martínez, R. Murciano, and M. A. Arribas, "Cobalt supported on morphologically tailored SBA-15 mesostructures: the impact of pore length on metal dispersion and catalytic activity in the Fischer-Tropsch synthesis," Applied Catalysis A: General, vol. 367, no. 1-2, pp. 149-159, 2009.

[111] H. D. Zhang, Y. Zou, Y. Shen et al., "Dominated effect analysis of the channel size of silica support materials on the catalytic performance of immobilized lipase catalysts in the transformation of unrefined waste cooking oil to biodiesel," BioEnergy Research, vol. 7, no. 4, pp. 1541-1549, 2014. 

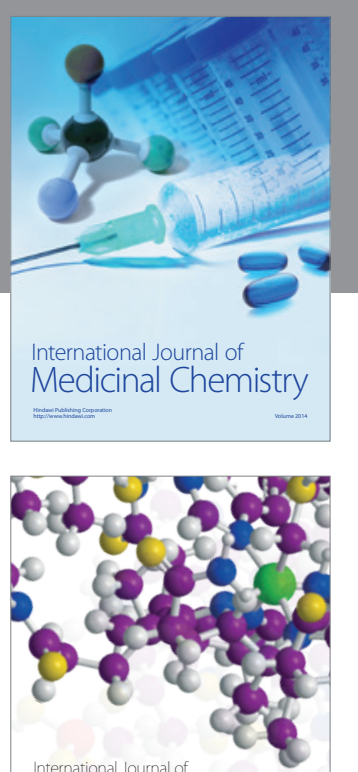

Carbohydrate Chemistry

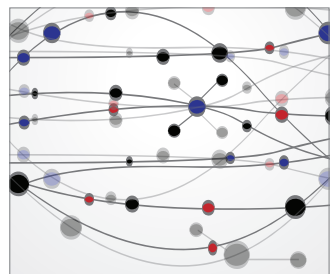

The Scientific World Journal
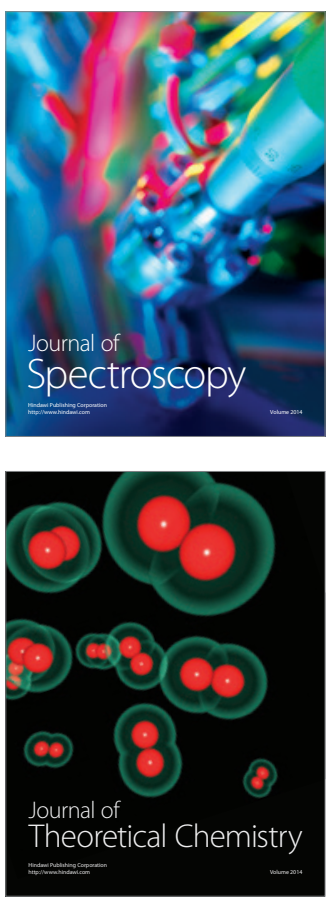
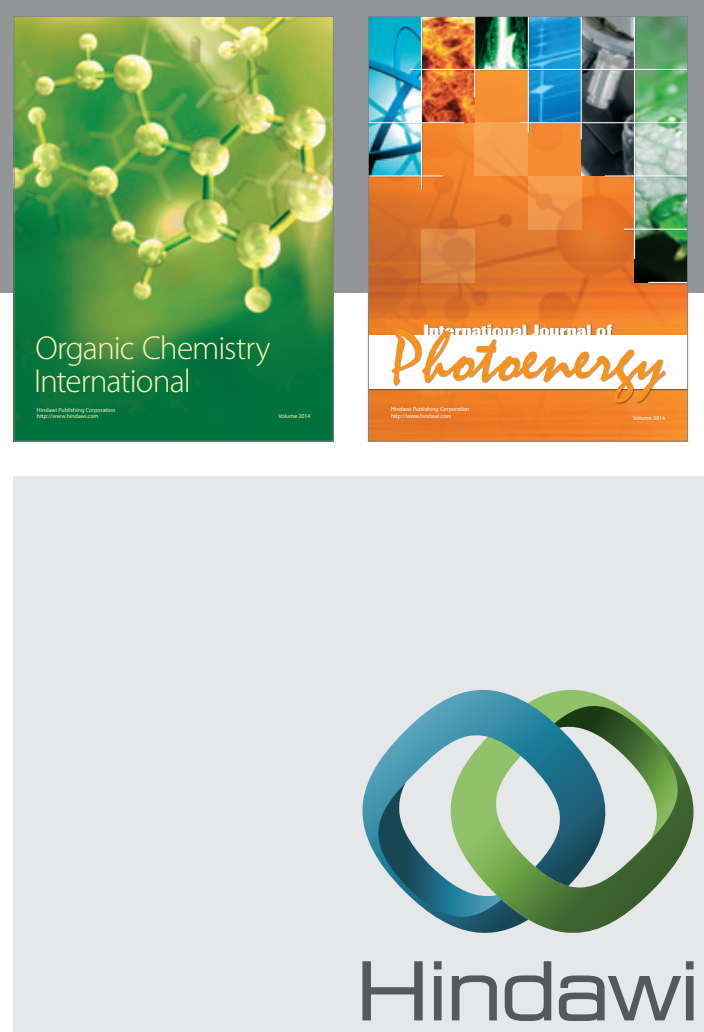

Submit your manuscripts at

http://www.hindawi.com

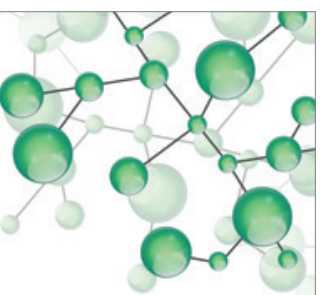

International Journal of

Inorganic Chemistry

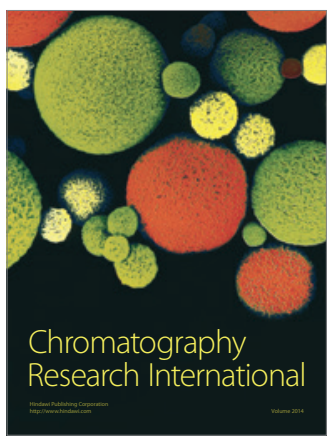

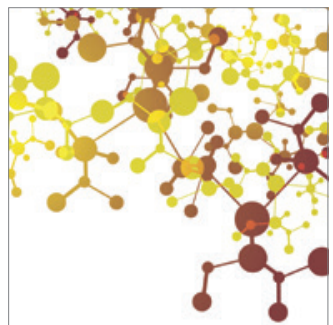

Applied Chemistry
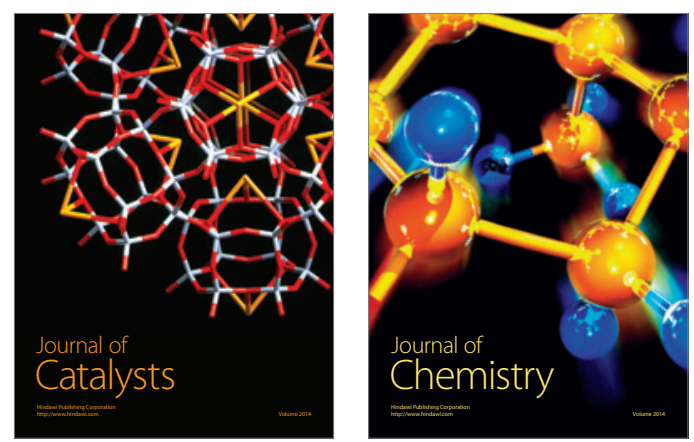
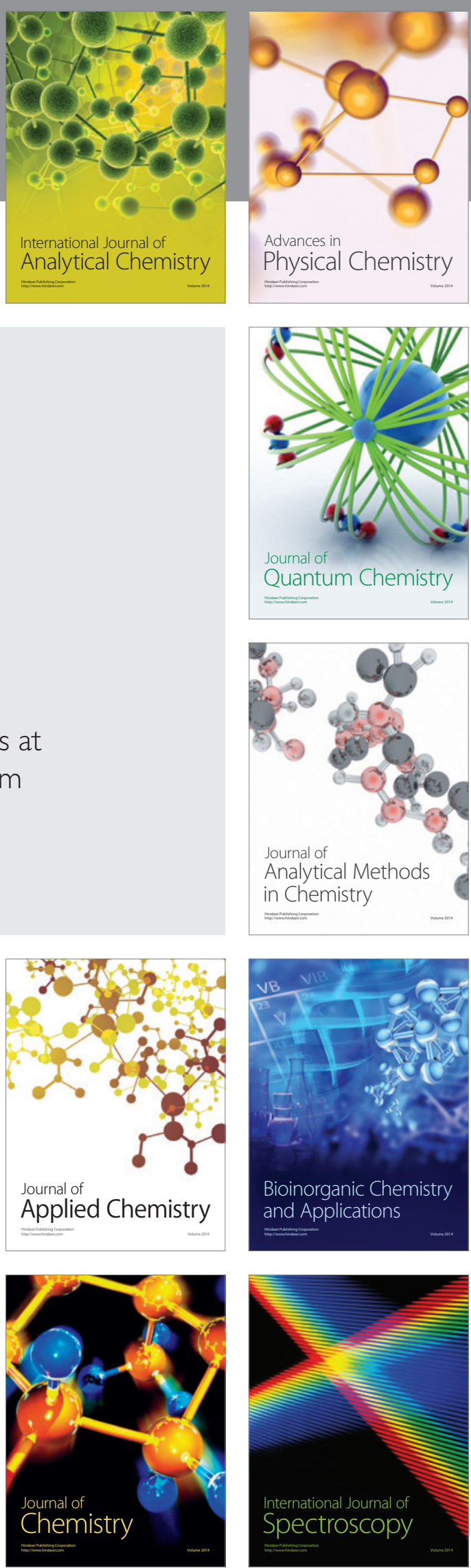